\title{
Major imprint of surface plankton on deep ocean prokaryotic structure and activity
}

\section{Clara Ruiz-González ${ }^{1}$ (D) | Mireia Mestre ${ }^{1,2,3}$ (D) | Marta Estrada ${ }^{1}$ (D) | Marta Sebastián ${ }^{1,4}$ (D) | Guillem Salazar $^{1,5}$ (D) | Susana Agustí ${ }^{(1)}$ | Enrique Moreno-Ostos ${ }^{7}$ (D) | Isabel Reche ${ }^{8}$ (D) | Xosé Antón Álvarez-Salgado9 (i) | Xosé Anxelu G. Morán ${ }^{6}$ (i) | Carlos M. Duarte ${ }^{6}$ (i) | M. Montserrat Sala ${ }^{1}$ (D) | Josep M. Gasol ${ }^{1,10}$ (D)}

${ }^{1}$ Institut de Ciències del Mar (ICM-CSIC), Barcelona, Spain

${ }^{2}$ Centro FONDAP de Investigación en Dinámica de Ecosistemas Marinos de Altas Latitudes (IDEAL), Universidad Austral de Chile, Valdivia, Chile

${ }^{3}$ Centro de Investigación Oceanográfica COPAS Sur-Austral, Departamento de Oceanografía, Universidad de Concepción, Concepción, Chile

${ }^{4}$ Instituto de Oceanografía y Cambio Global, IOCAG, Universidad de Las Palmas de Gran Canaria (ULPGC), Las Palmas, Spain

${ }^{5}$ Department of Biology, Institute of Microbiology and Swiss Institute of Bioinformatics, ETH Zurich, Zurich, Switzerland

${ }^{6}$ Red Sea Research Center (RSRC), King Abdullah University of Science and Technology, Thuwal, Saudi Arabia

${ }^{7}$ Department of Ecology and Geology, Marine Ecology and Limnology Research Group, CEIMAR, University of Málaga, Málaga, Spain

${ }^{8}$ Departamento de Ecología and Research Unit Modeling Nature (MNat), Universidad de Granada, Granada, Spain

${ }^{9}$ Instituto de Investigacións Mariñas (IIM-CSIC), Vigo, Spain

${ }^{10}$ Centre for Marine Ecosystems Research, School of Science, Edith Cowan University, Joondalup, WA, Australia

\section{Correspondence}

Clara Ruiz-González, Institut de Ciències del Mar (ICM-CSIC), Barcelona, Catalonia, Spain. Email: clararg@icm.csic.es, clara.ruiz.glez@ gmail.com

Funding information

Ministerio de Economía y Competitividad, Grant/Award Number: CSD2008-00077;

Ministerio de Ciencia e Innovación, Grant/

Award Number: RTI2018-099740-J-I00

\begin{abstract}
Deep ocean microbial communities rely on the organic carbon produced in the sunlit ocean, yet it remains unknown whether surface processes determine the assembly and function of bathypelagic prokaryotes to a larger extent than deep-sea physicochemical conditions. Here, we explored whether variations in surface phytoplankton assemblages across Atlantic, Pacific and Indian ocean stations can explain structural changes in bathypelagic (ca. 4,000 m) free-living and particle-attached prokaryotic communities (characterized through $16 \mathrm{~S}$ rRNA gene sequencing), as well as changes in prokaryotic activity and dissolved organic matter (DOM) quality. We show that the spatial structuring of prokaryotic communities in the bathypelagic strongly followed variations in the abundances of surface dinoflagellates and ciliates, as well as gradients in surface primary productivity, but were less influenced by bathypelagic physicochemical conditions. Amino acid-like DOM components in the bathypelagic reflected variations of those components in surface waters, and seemed to control bathypelagic prokaryotic activity. The imprint of surface conditions was more evident in bathypelagic than in shallower mesopelagic (200-1,000 m) communities, suggesting a direct connectivity through fast-sinking particles that escape mesopelagic transformations. Finally, we identified a pool of endemic deep-sea prokaryotic taxa (including potentially chemoautotrophic groups) that appear less connected to surface processes than those bathypelagic taxa with a widespread vertical distribution.
\end{abstract}


Our results suggest that surface planktonic communities shape the spatial structure of the bathypelagic microbiome to a larger extent than the local physicochemical environment, likely through determining the nature of the sinking particles and the associated prokaryotes reaching bathypelagic waters.

\section{KEYWORDS}

bacterial activity, carbon export, deep ocean, fluorescent dissolved organic matter, marine prokaryotic communities, microbial dispersal, particle sinking, particle-attached, surface phytoplankton

\section{1 | INTRODUCTION}

Microbial communities in the deep bathypelagic ocean $(1,000-$ 4,000 m depth) are assumed to be largely supported by surface-derived carbon delivered as sinking particles (Arístegui, Gasol, Duarte, \& Herndl, 2009; Herndl \& Reinthaler, 2013). It is thus intuitive to think that surface particle-formation processes may have an impact on the ecology and assembly of deep ocean microbial communities. Indeed, a few reports have shown changes in bathypelagic prokaryotic abundance or activity related to carbon fluxes or surface primary production (Hansell \& Ducklow, 2003; Nagata, Fukuda, Fukuda, \& Koike, 2000; Tamburini, Garcin, \& Bianchi, 2003; Yokokawa, Yang, Motegi, \& Nagata, 2013), and others have suggested a role of epipelagic conditions on shaping microbial community composition down to the mesopelagic layer (200-1,000 m) in Pacific ocean waters (Cram, Chow, et al., 2015; Cram, Xia, et al., 2015; Parada \& Furhman, 2017; Santoro et al., 2017). Furthermore, particles were recently proposed to directly transport surface prokaryotes (i.e., bacteria and archaea) down to the bathypelagic (Mestre et al., 2018), which suggests that this surface control on bathypelagic microbes may extend beyond the supply of surface-produced material. However, little is known about the mechanisms controlling the assembly of prokaryotes at layers deeper than the mesopelagic. In particular, whether variations in surface phytoplankton assemblages can determine the spatial structuring and function of the bathypelagic microbiome to a greater extent than the in situ physicochemical environment has never been investigated.

The amount, quality, size and sinking rates of the particles leaving the photic ocean are ultimately determined by the community structure of phytoplankton and other food web processes such as grazing (Bach et al., 2019; Boyd \& Newton, 1995; Guidi et al., 2009; Laurenceau-Cornec, Trull, Davies, De la Rocha, \& Blain, 2015; Stukel, Landry, Benitez-Nelson, \& Goericke, 2011). For example, diatoms and mesozooplankton are considered main drivers of carbon export due to fast sinking rates of large cells or dense faecal pellets, respectively (Agustí et al., 2015; Al-Mutairi \& Landry, 2001; Boyd \& Newton, 1995; Fender et al., 2019; Stukel et al., 2011), but multiple studies have unveiled that groups such as picoeukaryotes, radiolarians, ciliates, dinoflagellates and even picocyanobacteria can also be delivered at depth, probably as fast-sinking aggregates (Agustí et al., 2015; Amacher, Anderson, \& Massana, 2009; Boeuf et al., 2019; Fontánez, Eppley, Samo, Karl, \& DeLong, 2015; Guidi et al., 2016; Gutiérrez-Rodríguez et al., 2019; Lundgreen et al., 2019). Epipelagic planktonic assemblages may thus shape bathypelagic microbial communities by determining the quality and amount of the exported materials; for example, nutrients deriving from sinking particles were suggested to explain the propagation of temporal patterns in free-living microbial community composition between surface and mesopelagic waters (Cram, Xia, et al., 2015; Parada \& Furhman, 2017). In turn, different phytoplankton taxa may determine the pool of potential microbial colonizers reaching the deep ocean, given that different algal species harbour distinct associated prokaryotic communities (Grossart, Levold, Allgaier, Simon, \& Brinkhoff, 2005), and that intact photosynthetic phytoplankton cells were recovered at 4,000 m during the Malaspina global oceanographic expedition (Agustí et al., 2015).

Deep-sea prokaryotes may nonetheless be disconnected from surface processes. For example, the exported material may be entirely remineralized before reaching the bathypelagic (Arístegui, Agustí, Middelburg, \& Duarte, 2005), or could have been transported to the deep ocean by lateral advection (Baltar, Arístegui, Gasol, Sintes, \& Herndl, 2009; Hansell, Carlson, Bates, \& Poisson, 1997; Shih et al., 2019). In fact, a global bathypelagic survey conducted during the Malaspina expedition (Salazar, Cornejo-Castillo, Benítez-Barrios, et al., 2015) did not find evidence that deep-sea prokaryotic assemblages differed among Longhurst biogeographic provinces, characterized by different phytoplankton communities (Longhurst, 1998), although they did not consider the environmental conditions associated to each province and targeted communities from two small size-fractions potentially less prone to sink $(0.2-0.8 \mu \mathrm{m}$ and $0.8-$ 20 um; Salazar, Cornejo-Castillo, Benítez-Barrios, et al., 2015). In addition, microbial communities in the deep ocean may no longer reflect the original surface processes delivering the particles if the attached microbial communities change during sinking, or if the local bathypelagic physicochemistry plays a larger role in species sorting than the arriving material (Boeuf et al., 2019; Datta, Sliwerska, Gore, Polz, \& Cordero, 2016; Pelve, Fontánez, \& DeLong, 2017). Finally, the prevalence of autotrophic metabolisms among bathypelagic prokaryotes (Acinas et al., 2019; Pachiadaki et al., 2017; Swan et al., 2011), or the ability to use recalcitrant organic matter derived from old particles (Landry, Swan, Herndl, Stepanauskas, \& Giovannoni, 2017), could also lead to an apparent decoupling of bathypelagic microbial community structure from surface processes. Thus, besides particle origin and sinking rates and fluxes, the different lifestyles of the 


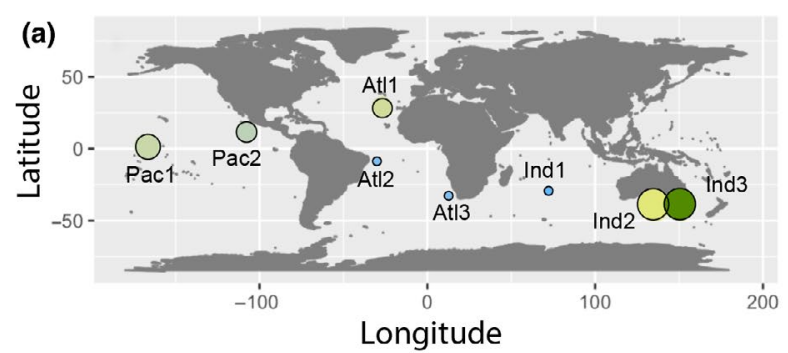

Longhurst

\begin{tabular}{cr}
\hline Chl. & Prod. \\
- 2 & 0.6 \\
4 & 0.5 \\
6 & 0.4 \\
8 & 0.3 \\
& 0.2
\end{tabular}

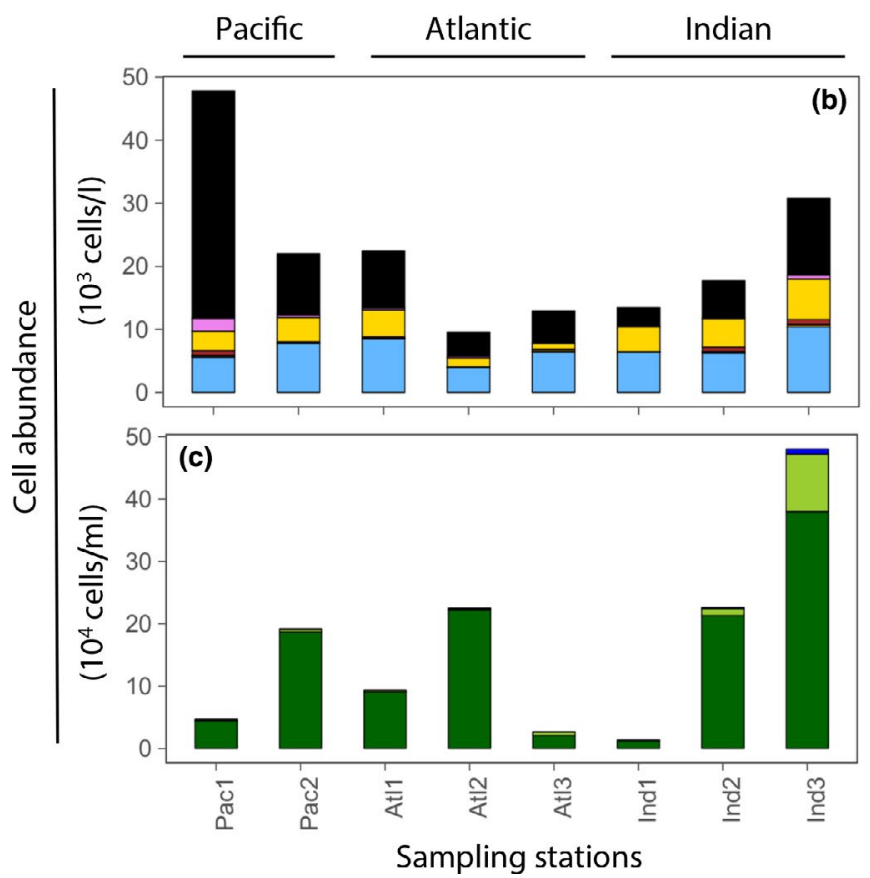

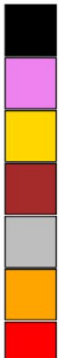

Coccolithophores

Diatoms

Dinoflagellates

Naked ciliates

Foraminifers

Tintinids

Radiolarians

Acantharians

Nanoflagellates

Picoeukaryotes

Synechococcus

Prochlorococcus
FIGURE 1 Differences in surface phytoplankton community composition and average productivity across the studied stations. (a) Map showing the location of the eight sampled stations. The size of the dot and the colour gradient indicate the mean annual chlorophyll over the photic layer and the mean daily rates of net primary production (Prod, $\mathrm{gC} \mathrm{m}^{-2}$ day $^{-1}$ ), respectively, associated with the Longhurst provinces to which each station belongs (see Table 1). (b-c) Cell absolute abundances of different eukaryotic and cyanobacterial plankton groups in the surface $(3 \mathrm{~m})$ waters of each station, measured by either inverted microscopy (b), or flow cytometry (c) [Colour figure can be viewed at wileyonlinelibrary.com] concentration (Chl, $\mathrm{mg} \mathrm{m}^{-2}$ ) integrated

taxa inhabiting the deep ocean (free-living versus particle-attached, autotrophic versus heterotrophic) may also control the extent of the influence of epipelagic processes on the bathypelagic microbiome by determining the immediacy of microbial responses to carbon supply.

By analysing prokaryotic communities attached to particles of different sizes (up to $200 \mu \mathrm{m}$ ), we recently observed that most of the bathypelagic prokaryotic taxa detected across eight oceanic stations were also present in surface waters, and that particle-attached communities at $3 \mathrm{~m}$ and 4,000 $\mathrm{m}$ displayed comparable spatial differences across stations (Mestre et al., 2018). Although we suggested the possibility of a vertical transfer of biogeographic patterns via the particle-driven delivery of surface prokaryotes, we did not identify the mechanisms behind these biogeographic patterns, nor whether the observed distribution of deep-sea prokaryotic assemblages was determined to any extent by surface conditions related to particle origin and formation. Here, we build on that study to assess whether the nature of surface phytoplankton communities can explain spatial variations in deep-sea prokaryotic community structure, and we compare it with the role of in situ bathypelagic physicochemical conditions. In addition, we explore whether surface conditions determine the composition of the dissolved organic matter (DOM) pool in the deep ocean, as sinking particles release DOM through solubilization by heterotrophic microbes (Herndl \& Reinthaler, 2013) and this could affect the structuring and activity of deep sea prokaryotes.
To do so, we compared variations in the composition of prokaryotic communities (free-living and attached to particles of different sizes) sampled down to $4,000 \mathrm{~m}$ at eight open-ocean stations (Mestre et al., 2018) to quantitative variations in surface micro-, nano- and picophytoplankton group abundances, average chlorophyll- $a$ concentration and productivity levels of the respective Longhurst provinces, and local bathypelagic environmental conditions, including proxies for fluorescent dissolved organic matter (FDOM) quality. We hypothesize that, due to the direct particle-driven inoculation of surface prokaryotes (Mestre et al., 2018), shifts in epipelagic phytoplankton communities should be related to the spatial structuring of bathypelagic prokaryotic assemblages, but this surface imprint should be progressively attenuated towards deeper waters. We also expect a surface influence on the quality of DOM in the bathypelagic, which might impact not only the prokaryotic community composition but also the heterotrophic activity.

\section{2 | MATERIALS AND METHODS}

\section{1 | Study area and sampling design}

Details of the studied stations and sampling can be found in Mestre et al. (2018), Morán et al. (2017) and Estrada et al. (2016). Briefly, 


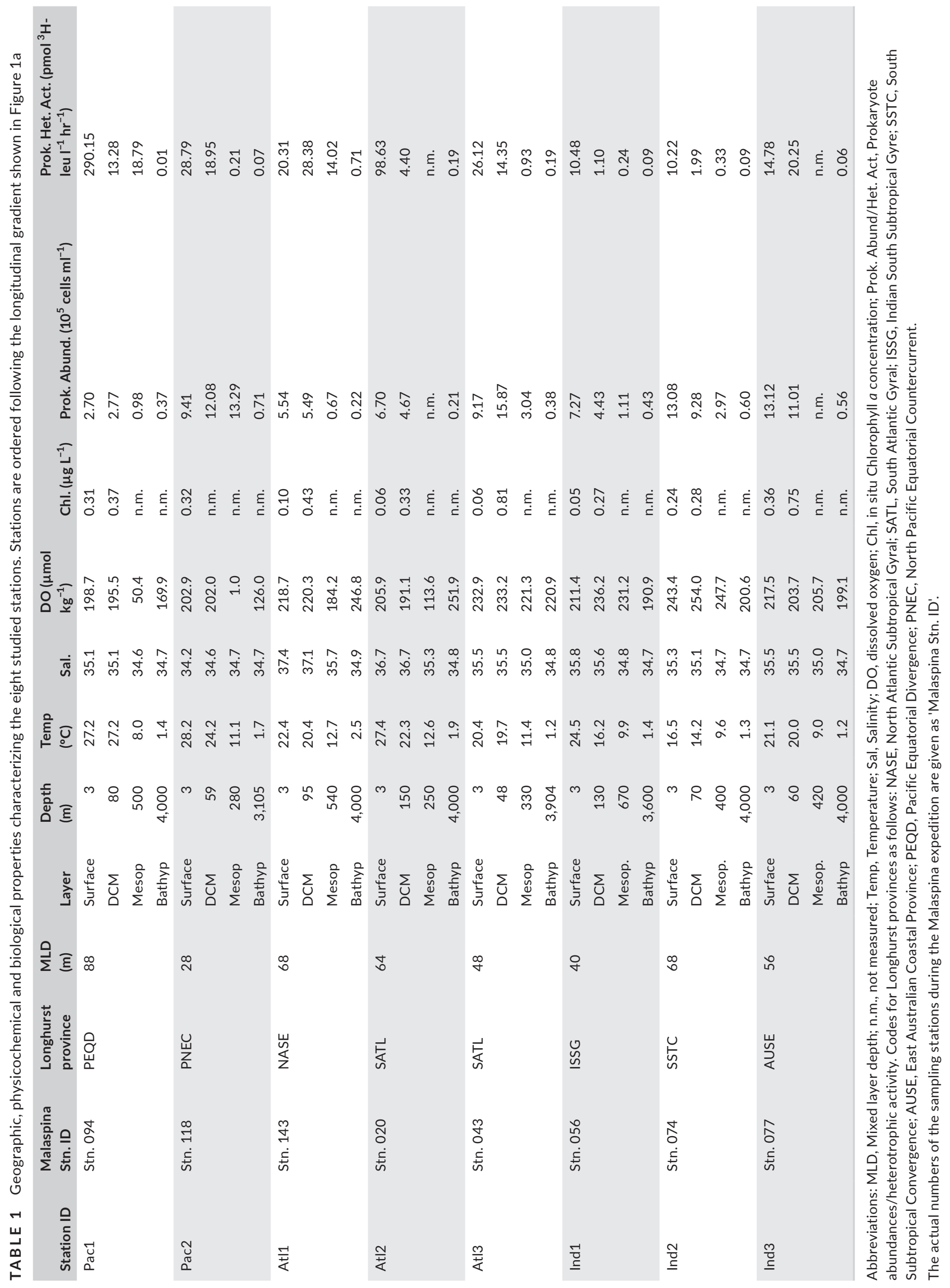


the sampling was carried out in eight stations distributed across the Atlantic, Pacific and Indian oceans (Figure 1a) as part of the Malaspina circumnavigation expedition (Duarte, 2015). At each station, water samples were collected with a Rosette sampling system fitted with twenty-three 10 L Niskin water sampling bottles (which can be remotely closed at the desired depth) and a conductivitytemperature-depth (CTD) probe, and with a $30 \mathrm{~L}$ Niskin bottle in the case of surface samples.

Four depths were sampled at each station (Table 1): surface $(3 \mathrm{~m})$, the depth of the deep chlorophyll- $a$ maximum (DCM, 48-150 m), mesopelagic (250-670 m), and bathypelagic waters (3,105-4,000 m). Inorganic nutrient concentrations at each depth (nitrate, phosphate, silicate) were determined as in Catalá et al. (2016). In those samples in which nutrient concentrations were not available, they were obtained from the data included in the World Ocean Atlas 2013 (WOA13) database (Garcia et al., 2014).

\section{2 | Microplankton, nanoplankton and picophytoplankton community composition}

Nanoplankton $(2-20 \mu \mathrm{m})$ and microplankton $(20-200 \mu \mathrm{m})$ communities from surface and DCM waters were sampled as detailed in Estrada et al. (2016). Briefly, samples were fixed with hexaminebuffered formaldehyde solution (4\% final concentration). For examination, $100 \mathrm{~cm}^{3}$ composite chambers were filled with each sample and left to settle for $48 \mathrm{hr}$. Quantification and identification of all the organisms was done using an inverted microscope at $312 \mathrm{X}$ or 125X magnification. Classification was done at the genus or species level when possible, but for the purpose of the present study we grouped organisms into major groups including: Total diatoms, dinoflagellates, naked ciliates, coccolithophores, acantharians, foraminifers, radiolarians, tintinnids and unidentified nanoflagellates (3-20 $\mu \mathrm{m}$ ). Picophytoplankton (Prochlorococcus, Synechococcus and photosynthetic picoeukaryotes) enumeration was done by flow cytometry as detailed in Agustí, Lubián, Moreno-Ostos, Estrada, and Duarte (2019).

\section{3 | In situ chlorophyll-a concentration and average properties of Longhurst provinces}

In situ chlorophyll-a (Chl) concentration in the studied surface waters was measured as detailed in Estrada et al. (2016). In addition, we used mean annual chlorophyll- $a$ concentration and primary production associated to the Longhurst province to which each station belonged as proxies for the annual average productivity conditions within the sunlit layer of each station. The partition of the ocean in Longhurst's biogeographic provinces is based on changes in physicochemical oceanic and atmospheric variables (e.g., turbulence, temperature, irradiance and nutrients) that determine phytoplankton distribution (Longhurst, 1998). Longhurst chlorophyll-a and productivity (hereafter Longhurst-Chl and Longhurst-pprod) data were downloaded from the Marine Regions site (http://www.marin eregions.org), and represent mean annual chlorophyll-a concentrations $\left(\mathrm{mg} \mathrm{m}^{-2}\right.$ ) and mean daily rates of net primary production ( $\mathrm{gC}$ $\mathrm{m}^{-2} \mathrm{~d}^{-1}$ ) integrated for the photic zone.

\subsection{Free-living prokaryotic abundances and bulk heterotrophic activity}

Total free-living prokaryotic abundances at each depth were determined by flow cytometry as described in Gasol and del Giorgio (2000). Bulk prokaryotic heterotrophic production for samples above $1,000 \mathrm{~m}$ was estimated using the ${ }^{3} \mathrm{H}$-leucine incorporation method (Kirchman, Knees, \& Hodson, 1985). Briefly, four aliquots $(1.2 \mathrm{ml})$ and two trichloroacetic acid (TCA)-killed controls (5\% final concentration) were incubated with ${ }^{3} \mathrm{H}$-leucine $\left(160 \mathrm{Ci} \mathrm{mmol}^{-1}\right.$, $20 \mathrm{nM}$ final conc.) for about 2-4 hr in the dark at in situ temperature. The incorporation was stopped by adding cold TCA ( $5 \%$ final concentration), and samples were processed by the centrifugation method of Smith and Azam (1992). For deeper samples (>1,000 m), two $40 \mathrm{ml}$ aliquots and two formaldehyde-killed controls (2\% final concentration) were incubated at in situ temperature with ${ }^{3} \mathrm{H}$-leucine (160 Ci mmol ${ }^{-1}, 5 \mathrm{nM}$ final concentration) for six up to $14 \mathrm{hr}$ depending on the expected activity. Incubations were stopped with formaldehyde ( $2 \%$ final concentration), samples were filtered through $0.2 \mu \mathrm{m}$ filters, rinsed three times with $5 \mathrm{ml}$ of cold TCA (5\%) and the radioactivity on dry filters was counted on a Beckman scintillation counter.

\section{5 | Analysis of fluorescent dissolved organic matter}

At each station and depth, DOM composition was described on the basis of fluorescence excitation/emission matrices (EEMs) as explained in Catalá, Reche, Fuentes-Lema et al. (2015). Four main fluorescence components were recovered from the EEMs using parallel factor analysis (PARAFAC): Components $\mathrm{C} 1$ and $\mathrm{C} 2$, previously related to refractory, humic-like material, and C3-C4, associated with more biolabile material of amino-acid like nature. In particular, the amino acid-like C3 and C4 have been attributed to tryptophan and tyrosine, respectively, shown to represent more biodegradable and fresher microbially-produced FDOM (for more details see Catalá, Reche, Fuentes-Lema et al. , 2015). The percentage contribution of each component was calculated relative to the summed maximum fluorescence of the four PARAFAC components.

\section{6 | Prokaryotic community composition}

The sampling for DNA extraction was carried out as explained previously in Mestre et al. (2018). Briefly, samples were collected by 
sequentially filtering $10 \mathrm{~L}$ through a $200 \mu \mathrm{m}$ mesh and 20, 5.0, 3.0, 0.8 , and $0.2 \mu \mathrm{m}$ pore-size filters with a peristaltic pump. At each station, communities associated with five different size fractions $(0.2-$ 0.8, 0.8-3.0, 3.0-5.0, 5.0-20, and 20-200 $\mu \mathrm{m}$ ) were recovered from the four sampled depths, representing free-living $(0.2-0.8 \mu \mathrm{m})$ assemblages as well as communities associated to particles of different sizes. A total of 155 communities were collected, because bathypelagic communities from station Ind1 (Table 1) could not be sampled. The characterization of prokaryotic communities was performed through Illumina sequencing of the $16 \mathrm{~S}$ rRNA gene using primers 515F and 926R (Parada, Needham, \& Fuhrman, 2016) and quality sequences were binned into operational taxonomic units (OTUs, $\geq 99 \%$ similarity), as explained in Mestre et al. (2018). To avoid redundancies when comparing with picophytoplankton flow cytometry data, cyanobacterial sequences were excluded prior to analyses, and the OTU table was rarefied to 7,000 reads per sample (except for 19 samples that had lower numbers -range 2,524-6,806 reads- but were nonetheless kept). Raw sequence data are publicly available in the European Nucleotide Database (ENA) under accession numbers ERP109198 and ERS2539749-ERS2539903. The complete nonrarefied OTU table, taxonomy table and environmental data used in this study table are provided as Tables S1-S4.

\section{7 | Functional annotation of prokaryotic taxa}

As unfortunately there is no available metagenomic information of bathypelagic bacterial communities associated with the different size-fractions considered in this study, we used an indirect method to roughly infer the functional potential of the detected prokaryotic taxa (Faprotax: Louca, Wegener-Parfrey, \& Doebeli, 2016). Faprotax converts the taxonomic microbial community profiles into putative functional profiles, based on the taxa present in the samples, their corresponding abundance, and the empirical evidence of metabolic phenotypes for the different taxa described in the literature.

\section{8 | Statistical analyses}

Spatial differences between prokaryotic communities at each depth were visualized using nonmetric multidimensional scaling (NMDS, metaMDS function, R Vegan package, Oksanen et al., 2015) based on Bray-Curtis distances. Differences in taxonomic composition among treatments were tested using ANOSIM (Analysis of Similarity, anosim function $R$ Vegan). The envfit function ( $R$ Vegan) was used to explore the correlations between the different environmental or surface variables and the NMDS taxonomic ordination patterns, after selecting in each case the best subset of environmental variables through the BIOENV approach (bioenv function $\mathrm{R}$ Vegan). BIOENV finds the combination of variables whose Euclidean distances (based on scaled values) have the maximum correlation with prokaryotic community dissimilarities (Clarke \& Ainsworth, 1993). The significance of the envfit associations was determined by 999 random permutations, and only significant variables were plotted onto the NMDS.

The role of individual physicochemical or surface biotic variables in explaining changes in prokaryotic communities (or in the quality of the DOM pool) within each ocean layer was first assessed by means of Mantel linear correlations (R Vegan). For each depth, distance matrices were constructed computing the Euclidean distances of each single variable and were correlated to either the Euclidean distances of the DOM matrix (i.e., the intensities of the four components, C1-C4), or the Bray-Curtis dissimilarities between prokaryotic communities at each ocean layer. For simplification, and based on our previous results showing that communities attached to the three largest fractions were more similar to each other and different from the two small ones (Mestre et al., 2018), these analyses were performed considering together the small $(0.2-0.8$ and $0.8-3 \mu \mathrm{m}$, $n=62)$ and large $(3-5,5-20$ and $20-200 \mu \mathrm{m}, n=93)$ size-fractions instead of the five size-fractions separately.

The relative importance of the local physicochemical conditions and surface biotic factors in explaining the spatial differences between prokaryotic communities was then assessed in more detail only for the bathypelagic ocean through generalized dissimilarity modelling (GDM, Ferrier, Manion, Elith, \& Richardson, 2007) using the gdm function (gdm R package, Manion et al., 2018). GDMs allow analysing and predicting spatial patterns of turnover in community composition along environmental gradients within a nonlinear framework. Specifically, GDMs account for two types of nonlinearity: (i) the nonlinear (curvilinear) relationships commonly observed between increasing environmental distance (e.g., differences in environmental properties) and community dissimilarity; and (ii) a variable rate of compositional changes along a given gradient (see Ferrier et al., 2007 for details). GDMs were fit separately to each of the five different prokaryotic size-fractions in the bathypelagic, using as predictors the local bathypelagic conditions (temperature, salinity, dissolved oxygen, nutrient concentrations and the four FDOM components C1-C4) and surface biotic factors (Longhurst$\mathrm{Chl}$ and primary production, in situ surface $\mathrm{Chl}-a$, and surface abundances of all the planktonic groups identified). Although the effect of latitude and longitude on variations in prokaryotic communities or in the FDOM pool was assessed via Mantel tests, dispersal limitation due to geographic distance was not considered in the GDMs due to the difficulty of interpreting geographical distances in the bathypelagic, where submerged landmasses and ocean circulation may determine the physical isolation between microbial communities independently of geographic position. All GDMs were fitted using a linear combination of three I-spline basis function (the default value in the gdm function). Predictor significance was tested using the gdm.varlmp function, with 250 permutations per step until only significant $(\alpha<0.05)$ variables remained in the model. The percentage of deviance explained by each GDM was recorded as the metric of model fitting, and the relative importance of each predictor was measured as the percent change in deviance (that is, comparing a model fit with the variable permuted and unpermuted). When we considered DCM rather than surface biotic variables as drivers of 
prokaryotic communities, essentially the same results were observed, but the patterns were generally weaker and less significant (details not shown). Given that in our previous study it was precisely in surface waters $(3 \mathrm{~m})$ where most of the prokaryotic diversity detected at any other depth was found (Mestre et al., 2018), we focused our exploration on the role of surface biotic properties.

Correlations between individual variables were calculated using the Pearson's correlation coefficient. Finally, we identified two pools of bathypelagic OTUs: "surface-related" OTUs, i.e., bathypelagic taxa that were also detected in any sunlit surface or DCM sample, and "endemic" OTUs, i.e., bathypelagic taxa that were never detected in surface or DCM samples. All analyses were run using the R software version 3.5.3 (R Core Team, 2013).

\section{3 | RESULTS}

The stations sampled were distributed across the temperate and equatorial Atlantic, Pacific and Indian oceans and belonged to seven Longhurst provinces (Table 1) ranging widely in average annual chlorophyll-a (Chl) concentration and productivity levels (Figure 1a). The surface waters at each station differed in temperature, salinity, Chl (range 0.06-0.36 $\mu \mathrm{g} \mathrm{Chl} \mathrm{L}^{-1}$ ) and heterotrophic prokaryote

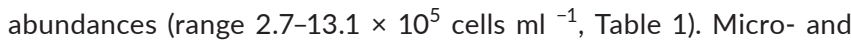
nanoplankton communities also varied across stations, both in terms of total abundance (range 9,600-47,800 cells $\mathrm{L}^{-1}$ in surface, and $6,100-72,500$ cells $L^{-1}$ at the DCM) and in the contribution of different eukaryotic groups to total cell counts (Figure 1b,c, Figure S1). In general, and aside from picophytoplankton, the surface planktonic assemblages were numerically dominated by coccolithophores, small nanoflagellates $(3-20 \mu \mathrm{m})$ and dinoflagellates (Figure $1 \mathrm{~b}$ ). Diatoms showed generally low abundances $\left(<650\right.$ cells $\left.\mathrm{L}^{-1}\right)$ except in the Equatorial Pacific (Stn. Pac1, >2,000 cells L ${ }^{-1}$ ), where the highest abundances of coccolithophores were also observed $(>36,000$ cells $\mathrm{L}^{-1}$, Figure 1b). Picophytoplankton assemblages were dominated by Prochlorococcus cyanobacteria in all cases, with Synechococcus comprising between $0.8 \%$ and up to $19 \%$ of the total picocyanobacteria in Stns. Atl3 and Ind3, respectively (Figure 1c). Photosynthetic picoeukaryotes ranged between 120 and 8,200 cells ml ${ }^{-1}$. Patterns at the DCM were similar to those of surface communities, with the exception of Stn. Atl3, which showed the shallowest DCM and much higher abundances of photosynthetic cells than in the overlying surface waters, and station Stn. Ind2, which showed comparably lower cells abundance than in surface waters (Figure S1).

The composition of the fluorescent fraction of DOM at each layer (in terms of the four components identified by PARAFAC) showed spatial variations that were not related to changes in phytoplankton communities across surface and DCM waters, but changed largely with depth (Figure S2). Sunlit waters were dominated by the labile amino acid-like FDOM components C3 and C4, which decreased pronouncedly towards the bathypelagic, whereas clear increases in the contribution of the humic-like FDOM components C1 and C2 were observed with depth. The more recalcitrant C1 and
C2 dominated the bathypelagic FDOM pool in all stations except in Atl1, where C3 and C4 showed increased fluorescence intensity (Figure S2a). As expected, the activity and abundance of free-living prokaryotes decreased pronouncedly from surface to bathypelagic waters (Table 1).

\section{1 | Spatial variability of prokaryotic communities at different depths}

The NMDS ordination of prokaryotic communities at each depth showed a clear segregation between small and large size-fractions in surface, DCM and mesopelagic waters (Figure 2a-c), but not in bathypelagic waters (Figure 2d). Interestingly, of all the variables tested, only Longhurst-Chl, in situ surface $\mathrm{Chl}$ concentration, proportion of amino acid-like FDOM component C3 (\%C3) and the surface abundances of dinoflagellates and nanoflagellates appeared to be significantly related to the NMDS ordination patterns. In particular, bathypelagic communities showed a very clear clustering based on the Longhurst-Chl gradient in overlying surface waters (ANOSIM byLonghurst_Chl $=0.71, p=.001$, Figure $2 \mathrm{~d}$ ), which was more important than the clustering of communities based on ocean basin $\left(\right.$ ANOSIM $_{\text {byOcean }}=0.51, p=.001$, Figure $2 d$ ).

\subsection{Drivers of prokaryotic communities or DOM composition throughout the water column}

Mantel tests showed that differences in in situ surface Chl concentration and average annual $\mathrm{Chl}$ values among Longhurst provinces (Longhurst-Chl) were strongly correlated with taxonomic changes in prokaryotic communities across stations, at the surface but also in mesopelagic and bathypelagic waters (Figure 3). Among the planktonic groups studied, spatial (i.e., horizontal) variations in surface dinoflagellate and ciliate abundances showed the strongest correlations with taxonomic changes in prokaryotic assemblages at both surface and deeper layers. Interestingly, bathypelagic communities from the largesize fractions responded to spatial differences in surface biotic variables in almost the same way than their surface counterparts, as the $\mathrm{R}$ coefficients of the respective significant Mantel correlations covaried strongly and positively (Figure S3c). This pattern was not as clearly maintained when comparing with mesopelagic and DCM communities (Figure S3a,b), which showed a lower number of significant Mantel correlations than surface and bathypelagic prokaryotes (Figure 3).

In contrast, surface biotic conditions did not appear to influence the DOM pool; we did not find any significant correlation between variations in surface biotic properties and changes in FDOM quality across stations (Figure S2c, Figure S4), and all the variability in FDOM was attributed to changes in physicochemical conditions at each depth. However, compositional changes in the bathypelagic FDOM were strongly linked to variations in the amino acid-like components C 3 and C4 from surface waters (Mantel $R=0.67$ and 0.84 , respectively, $p<.001$, Figure $\mathrm{S} 4$ ). 


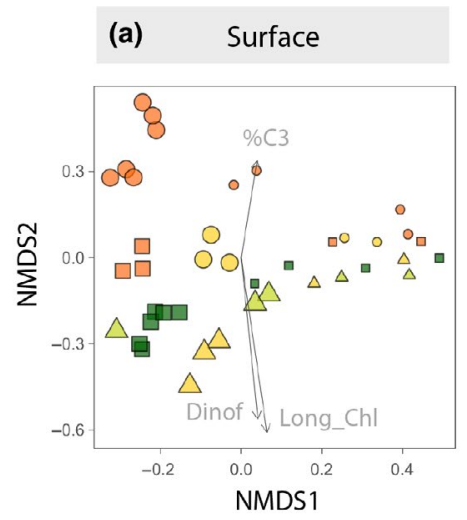

(c)

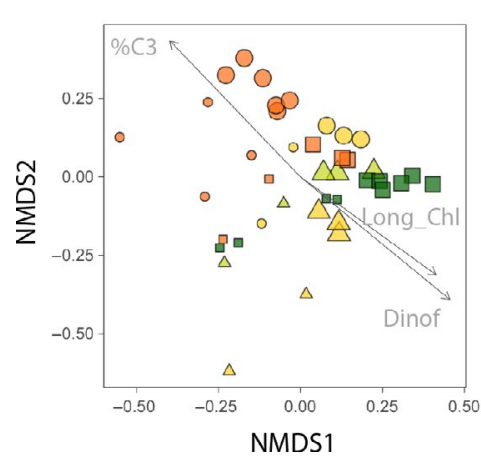

(b) DCM

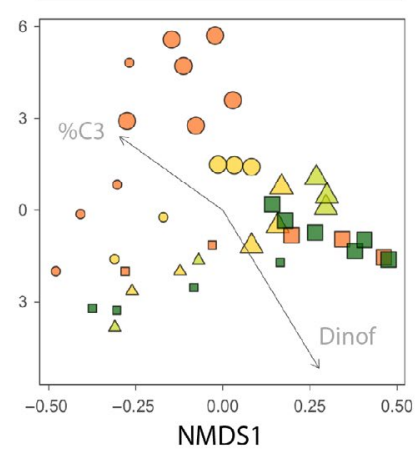

(d)

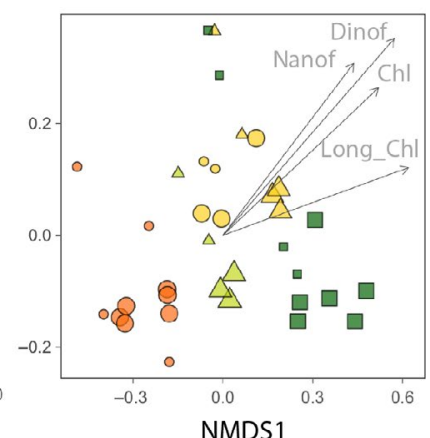

Size-fractions

○\{ $\left\{\begin{array}{l}0.2-0.8 \mu \mathrm{m} \\ 0.8-3 \mu \mathrm{m}\end{array}\right.$

$\left\{\begin{array}{l}3-5 \mu \mathrm{m} \\ 5-20 \mu \mathrm{m} \\ 20-200 \mu \mathrm{m}\end{array}\right.$

Ocean

○ Atlantic

口 Indian

$\triangle$ Pacific

Longhurst_Chl $\left(\mathrm{mg} / \mathrm{m}^{2}\right)$

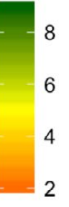

FIGURE 2 Spatial patterns of prokaryotic communities at each ocean layer. NMDS ordination of prokaryotic communities from each depth based on Bray-Curtis dissimilarities. The symbols indicate the different oceans, and samples are colour-coded according to mean annual chlorophyll- $a$ concentration $\left(\mathrm{mg} \mathrm{m}^{-2}\right.$ ) of each overlying Longhurst province (Longhurst_Chl, see Table 1 and Figure 1a). The size of the symbols indicates the size fraction, either small (i.e., 0.2-0.8 and 0.8-3 $\mu \mathrm{m}$, small symbols) or large (i.e., 3-5, 5-20 and 20-200 $\mu \mathrm{m}$, large symbols). The arrows indicate the local physicochemical variables or the surface biotic conditions that fit best onto the NMDS ordination space (envfit analysis, see Section 2). C3, percentage of fluorescent FDOM component C3; Long_Chl, mean annual Chl concentration of each overlying Longhurst province; Dinof, Nanof, surface abundances of dinoflagellates or nanoflagellates, respectively; Chl, measured chlorophyll- $a$ concentration in surface waters [Colour figure can be viewed at wileyonlinelibrary.com]

\section{3 | Role of in situ physicochemistry versus surface biotic conditions in bathypelagic community assembly}

The fact that both local physicochemical and surface biotic variables showed significant Mantel correlations with prokaryotic communities at all depths (Figure 3) suggests that different mechanisms may be simultaneously controlling the assembly of prokaryotic communities in the deep ocean. For example, community differentiation along bathypelagic environmental gradients might imply local selection of species occurring in the deep ocean, whereas taxonomic changes linked to surface properties might point to a direct or indirect influence of surface biological processes related to particle formation and sinking. In order to disentangle the relative importance of these two mechanisms in the assembly of bathypelagic communities associated with each of the different size-fractions, we used generalized dissimilarity modelling (GDM) including both bathypelagic physicochemical and surface biotic predictors (Figure 4). The best models explained between $91 \%$ to $98 \%$ of the variation in the observed taxonomic dissimilarity of bathypelagic assemblages from the five size-fractions (Figure 4a-e, Figure S5), and the selection of predictors highlighted a more important role of surface variables than local environmental conditions in all cases (Figure 4). Taxonomic changes in free-living (0.2-0.8 $\mu \mathrm{m}$ ) communities across bathypelagic stations appeared related to surface abundances of the cyanobacteria Synechococcus and Prochlorococcus (Figure 4a). Conversely, Longhurst-Chl was identified as the most important determinant of community turnover in bathypelagic assemblages from size-fractions 0.8-3, 5-20 and 20-200 $\mu \mathrm{m}$ (Figure 4b,d,e). The proportion of the amino acid-like C3 (\%C3) appeared to be relevant in size-fraction 3-5 $\mu \mathrm{m}$, although taken together, the selected surface variables had a more important role (Figure 4c). When Longhurst-Chl was excluded, however, \%C3 emerged as the main predictor in three of the particle-attached fractions (details not shown).

\section{4 | Vertical connectivity of prokaryotic communities along surface gradients}

If the observed reflection of surface conditions is due to the particle-driven delivery of surface taxa (Mestre et al., 2018), bathypelagic prokaryotic communities should be more similar to those from overlaying surface waters in sites with high particle export rates. 


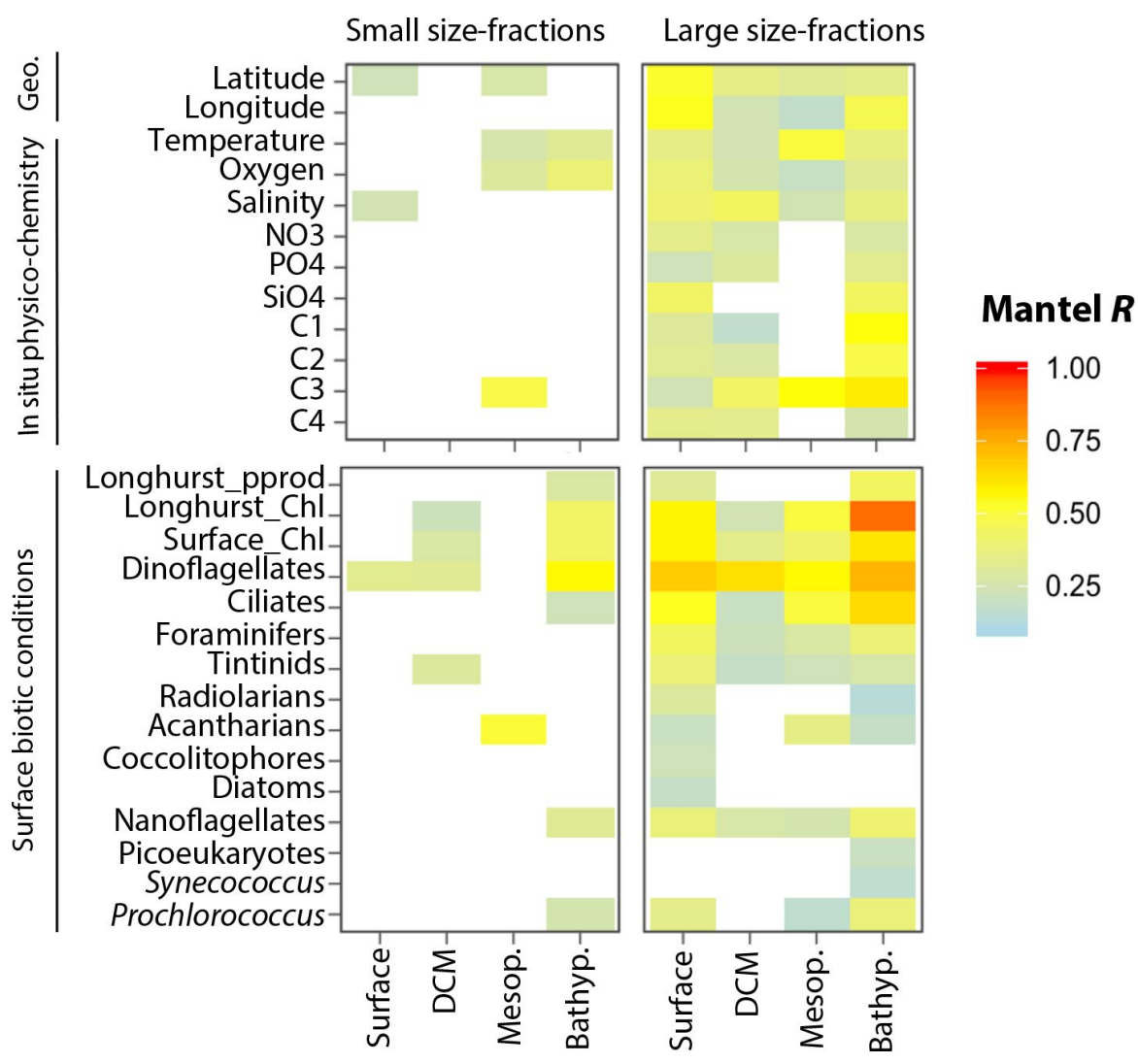

FIGURE 3 Role of in situ physicochemistry and surface biotic factors on shaping prokaryotic communities at each ocean layer. Heatmap showing $\mathrm{R}$ coefficients of the Mantel correlations between prokaryotic community (BrayCurtis) dissimilarity across stations and spatial differences (Euclidean distances) in individual geographic (Geo.) or local environmental variables measured at each depth, or in surface biotic variables, including mean annual chlorophyll-a concentration and primary production of each overlying Longhurst province (Longhurst_Chl, Longhurst_pprod), measured chlorophyll- $a$ concentration in surface waters ( $3 \mathrm{~m}$, Surface Chl), and surface abundances of the different micro-, nano- and pico- planktonic groups. Prokaryotic assemblages are split between small (0.2-0.8 and 0.8-3 $\mu \mathrm{m})$ and large (3-5, 5-20 and 20-200 $\mu \mathrm{m})$ size-fractions. Only R coefficients of significant correlations are shown $(p<.05)$ [Colour figure can be viewed at wileyonlinelibrary.com]
We computed the vertical dissimilarity between surface and deep (meso- and bathypelagic) prokaryotic communities at each station, and explored whether this vertical dissimilarity changed along surface productivity gradients. Surface and deep prokaryote communities were increasingly similar (i.e., lower Bray-Curtis dissimilarity between each other) towards more productive sites (i.e., higher Longhurst-Chl and primary production, where higher particle export might be expected), but this was only apparent for communities attached to the largest particles (Figure 5).

\section{5 | Drivers of bathypelagic prokaryotic abundance and heterotrophic activity}

We investigated whether any of the studied physicochemical or surface biotic variables could explain the observed patterns in free-living prokaryotic abundance and bulk heterotrophic activity measured at each depth. These two variables were not correlated across the studied stations. Prokaryotic abundance was not related to surface biotic variables in any case (Figure 6a). In the bathypelagic, only dissolved oxygen, salinity, nutrients and the FDOM component $\mathrm{C} 1$ showed significant relationships with prokaryote numbers (Figure 6a). Surface prokaryotic activity showed strong positive correlations with the abundances of foraminifers, tintinnids, coccolithophores and diatoms, and no variable appeared significantly related to prokaryotic activity in the DCM (Figure 6b). In deeper layers, the in situ physicochemical conditions, in particular the quality of FDOM, were the most important drivers of prokaryotic activity, and no significant relationship was found with surface biotic parameters (Figure 6b). In the bathypelagic in particular, strong positive correlations were found with the absolute fluorescence intensity of the humic-like FDOM component C2 and the amino acid-like components C3 and C4 measured in the bathypelagic. Surprisingly, bathypelagic prokaryotic activity also responded positively to variations in $\mathrm{C} 3$ and C4 in the overlying surface waters (Figure 6b).

The latter observation was likely due to the fact that both bathypelagic FDOM components C3 and C4 strongly covaried with their surface counterparts; i.e., stations with higher fluorescence intensities of C3 and C4 in surface waters had also more C3 and C4 in the bathypelagic, and this was not observed for the humic-like $\mathrm{C} 1$ and $\mathrm{C} 2$ FDOM components (Figure 6f,g). This covariation was only found in the bathypelagic, but not in upper mesopelagic waters (Figure 6c,d). In consequence, the strong positive correlation between bathypelagic prokaryotic activity and the intensity of C3 and C4 (Figure 6h) was not found in the mesopelagic, where $\mathrm{C} 4$ actually showed an opposite negative correlation with prokaryotic activity (Figure 6e).

\section{6 | Surface-related versus endemic deep ocean prokaryotes}

The above patterns suggest that, besides delivering surface prokaryotes (Mestre et al., 2018), sinking particles influence the dissolved organic matter environment in the deep ocean, which in turn modulates the bulk activity of the bathypelagic prokaryotic communities. In order to distinguish bathypelagic OTUs that 
(a) $\quad 0.2-0.8 \mu \mathrm{m}$
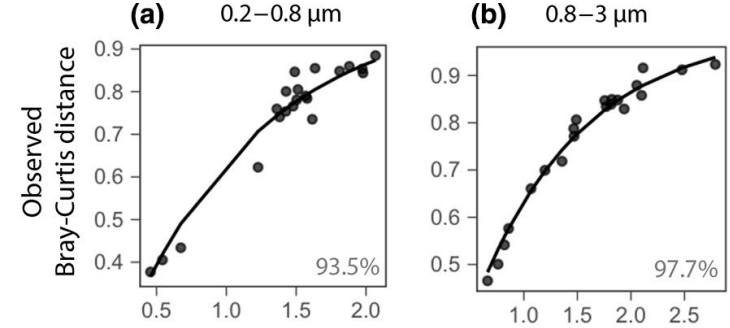

(c) $\quad 3-5 \mu \mathrm{m}$

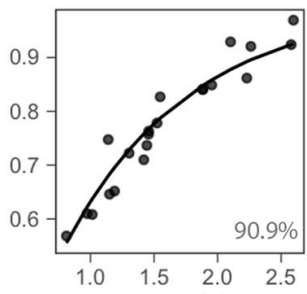

Environmental distance (d) $\quad 5-20 \mu \mathrm{m}$

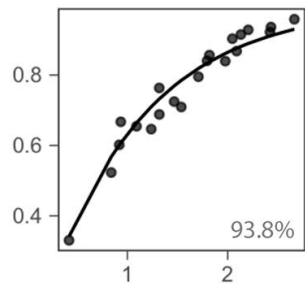

(e) $20-200 \mu \mathrm{m}$

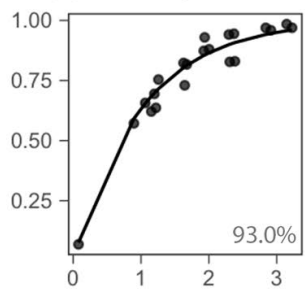

Importance of predictors in GDMs (\% of change in deviance)
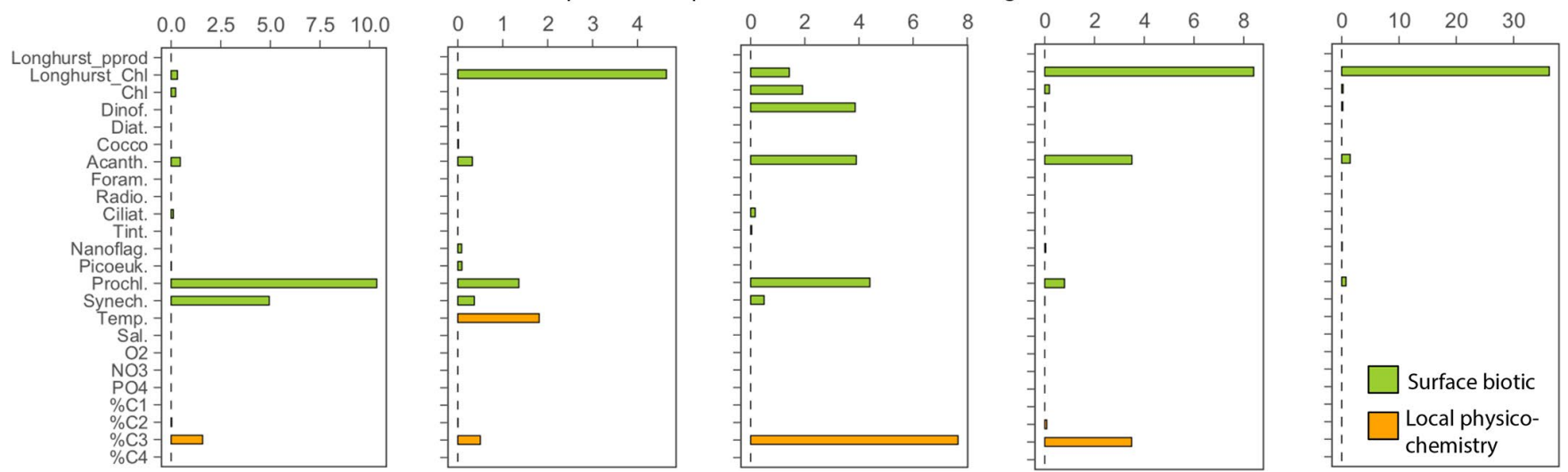

FIGURE 4 Surface biotic conditions drive the taxonomic structure of bathypelagic prokaryotes. Generalized dissimilarity modelling (GDM) was used to predict the taxonomic changes in bathypelagic prokaryotic communities associated to each size-fraction (a-e) in relation to different factors. The model fit to the relationship between the Bray-Curtis dissimilarity and the environmental distance (after I-spline transformation of each predictor, see Section 2) is shown in the upper panels, where the percentage of total taxonomic variation in prokaryotic communities explained by each model is also indicated (grey numbers). The importance of the predictors used to fit each model is indicated by the height of the bars in the lower panels as \% of deviance (see Section 2). The colours indicate whether the predictors are surface biotic variables (green) or local bathypelagic physicochemical factors (orange). Abbreviations of predictors: Mean annual chlorophylla concentration (Longhurst_Chl) or primary production (Longhurst_pprod) of each overlying Longhurst province; Chl, measured chlorophyll- $a$ concentration in surface waters; in situ temperature (Temp.), salinity (Sal.), dissolved oxygen $\left(\mathrm{O}_{2}\right)$, nitrate $\left(\mathrm{NO}_{3}\right)$, phosphate $\left(\mathrm{PO}_{4}\right)$ and silicate $\left(\mathrm{SiO}_{4}\right)$ concentrations, percentage of fluorescent FDOM components C1-C4 (\%C1-\%C4), surface abundances of dinoflagellates (Dinof), ciliates (Cil), tintinnids (Tint), nanoflagellates (Nanoflag), acantharians (Acanth), radiolarians (Radio), foraminifers (Foram), coccolithophores (Cocco), diatoms (Diat), photosynthetic picoeukaryotes (Picoeuk), Synechococcus (Synech) and Prochlorococcus (Prochl) [Colour figure can be viewed at wileyonlinelibrary.com]

may have been delivered with particles from those that are exclusively found in the deep ocean, we identified "surface-related" OTUs (i.e., bathypelagic OTUs also detected in sunlit-surface and DCM-waters) and "endemic" bathypelagic OTUs (i.e., bathypelagic OTUs not detected in any sunlit sample). The endemic and surface-related components of bathypelagic communities comprised completely different phylogenetic groups; whereas classes like Actinobacteria, Alphaproteobacteria, Gammaproteobacteria and Flavobacteriia dominated the surface-related component (Figure 7a), Thaumarchaeota, Deltaproteobacteria, OM190 and Planctomycetacia prevailed among the bathypelagic endemic taxa (Figure 7b). Surface-related OTUs numerically dominated all assemblages, whereas the endemic component comprised between $1 \%$ and $10 \%$ of bathypelagic community sequences. It is important to note, however, that our data are compositional and we do not have estimates of the actual abundances of prokaryotes associated to the different particle fractions; it is thus possible that the contribution of the endemic pool to the total community is larger than what our size-fractionation data suggest.
The community structure of the surface-related bathypelagic OTUs followed the same surface biotic gradients observed before for the whole communities (Figures $7 \mathrm{c}$ and $2 \mathrm{~d}$ ). Endemic bathypelagic OTUs, conversely, did not reflect such surface variations and appeared mostly related to local variations in temperature, and in the percentage of the FDOM components C1 and C3 (Figure 7d). An indirect estimation of the potential metabolic functions associated with these two taxa pools using FAPROTAX (see Section 2) showed a significantly higher proportion of chemolithoautotrophic metabolisms present among the endemic than among the surface-related bathypelagic OTUs (Figures S6a,b). Within the large-size fractions, the proportion of chemolithoautotrophic metabolisms associated to the endemic bathypelagic and surface-related components varied across stations depending on surface productivity. For example, surface-related assemblages showed the highest proportions of chemolithoautotrophic metabolisms in sites belonging to the most oligotrophic Longhurst provinces (Longhurst-Chl $=2 \mathrm{mg} \mathrm{m}^{-2}$ ), and autotrophic metabolisms associated with endemic bathypelagic OTUs were only detected in stations with Longhurst-Chl values lower than $4 \mathrm{mgm}^{-2}$ (Figure S6b). 


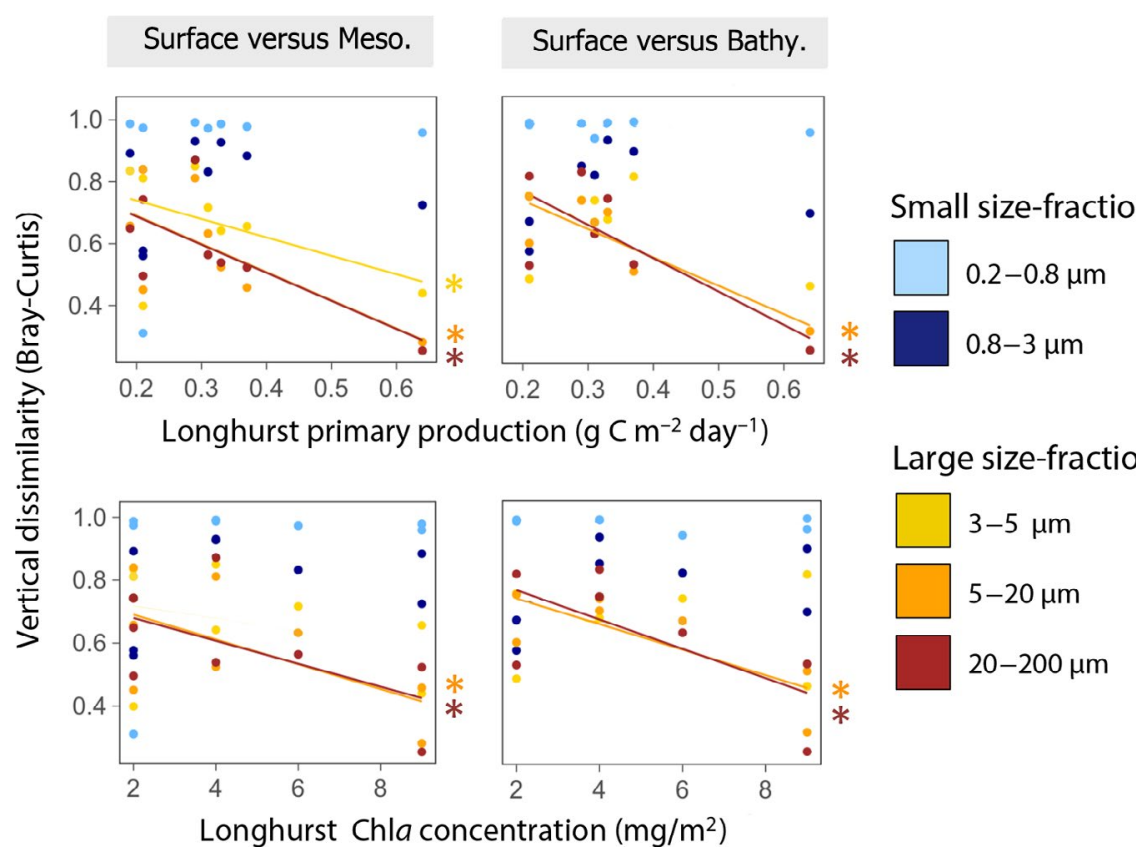

FIGURE 5 Higher surface primary productivity is associated with stronger vertical connectivity in particle-attached prokaryotic communities. Variation in vertical taxonomic differences (BrayCurtis dissimilarity) between surface and mesopelagic (Meso.), or between surface and bathypelagic (Bathy.) prokaryotic communities along gradients in average annual chlorophyll-a concentration and mean annual primary productivity of Longhurst provinces for each of the five size fractions. Asterisks $\left({ }^{*}\right)$ indicate significant $(p<.05)$ relationships (all $p$-values < .0001) [Colour figure can be viewed at wileyonlinelibrary.com]

\section{4 | DISCUSSION}

Our recent finding that sinking particles transport prokaryotes from surface to bathypelagic waters (Mestre et al., 2018) suggests that the influence of epipelagic processes on the deep-sea microbiome extends beyond the delivery of photosynthetically-produced material (Arístegui et al., 2009; Herndl \& Reinthaler, 2013). However, most recent efforts to characterize the global biogeography or the functional potential of bathypelagic microorganisms have focused exclusively on the bathypelagic layer itself, disregarding the potential connectivity with surface stocks or processes (Acinas et al., 2019; Pernice et al., 2015, 2016; Salazar, Cornejo-Castillo, BenítezBarrios, et al., 2015; Salazar, Cornejo-Castillo, Borrull, et al., 2015). Here, we show a link between the spatial structure of bathypelagic prokaryotic assemblages and planktonic community composition in the overlying surface waters. Our results suggest that the processes that control the quality and amount of particles produced in the surface shape bathypelagic prokaryotic assemblages to a larger extent than the bathypelagic physicochemical environment, and thus should be carefully considered in future deep sea microbial ecology studies.

\subsection{Surface biotic processes determine the structure of deep ocean prokaryotic communities}

The stations sampled covered a relatively wide gradient of surface conditions and average productivity levels across the subtropical and tropical waters, since they belonged to seven different Longhurst provinces (Longhurst, 1998). This was reflected in variations in the abundances of surface micro-, nano- and pico-photosynthetic and heterotrophic organisms, which probably translated into diverse food-web structures and interactions that ultimately modulate the export fluxes and the nature of the sinking particles reaching the deep ocean (Bach et al., 2016; Boeuf et al., 2019; Guidi et al., 2009; Stukel et al., 2011).

Accordingly, of all the variables tested, surface conditions such as Longhurst-associated chlorophyll- $a$ or the abundances of certain planktonic groups such as dinoflagellates, ciliates and nanoflagellates, many of which were heterotrophic, explained shifts in prokaryotic communities associated particles of different sizes at all depths, more so than local environmental variables measured at each site. Despite the obvious link between phytoplankton community structure and particle formation, only a few studies have considered phytoplankton diversity among the factors potentially driving the biogeography of marine particle-attached prokaryotes (e.g., SisonMangus, Jiang, Kudela, \& Mehic, 2016). Our results suggest that the surface abundances of major planktonic groups are strong determinants of the structure of particle-associated prokaryotic communities at depth, and highlight that this role might be obscured using approaches such as $18 \mathrm{~S}$ rRNA amplicon sequencing, which do not yield absolute abundances of taxa (Piwosz et al., 2020).

Coccolithophores and diatoms did not explain any change in prokaryotic assemblages from layers other than the surface. This was unexpected due to the numerical dominance of the former group across our stations and the fast sinking rates reported for diatoms even during the same expedition (Agustí et al., 2015). However, it is important to note that we did not measure carbon export or settling particles, and thus this surface signature may not reflect the sinking efficiency of specific plankton groups, but rather structural differences in surface planktonic communities associated with varying carbon fluxes. For instance, a dominance of dinoflagellates, ciliates and nanoflagellates may represent mature communities for which some export had already occurred (Hansen, Ohde, \& Wasmund, 2014; Schmoker, Ojeda, \& HernándezLeon, 2014), or assemblages where intense particle production 

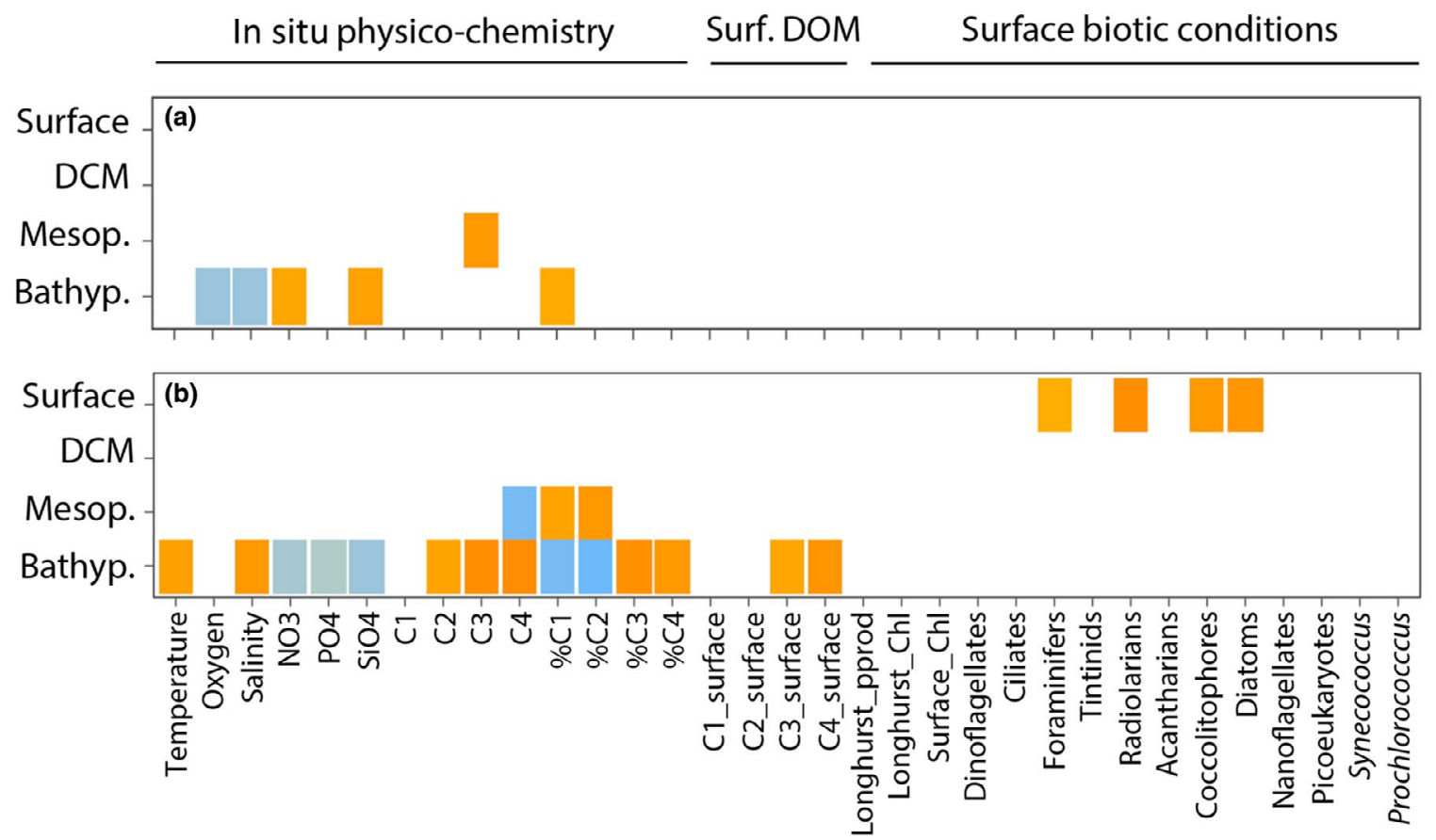

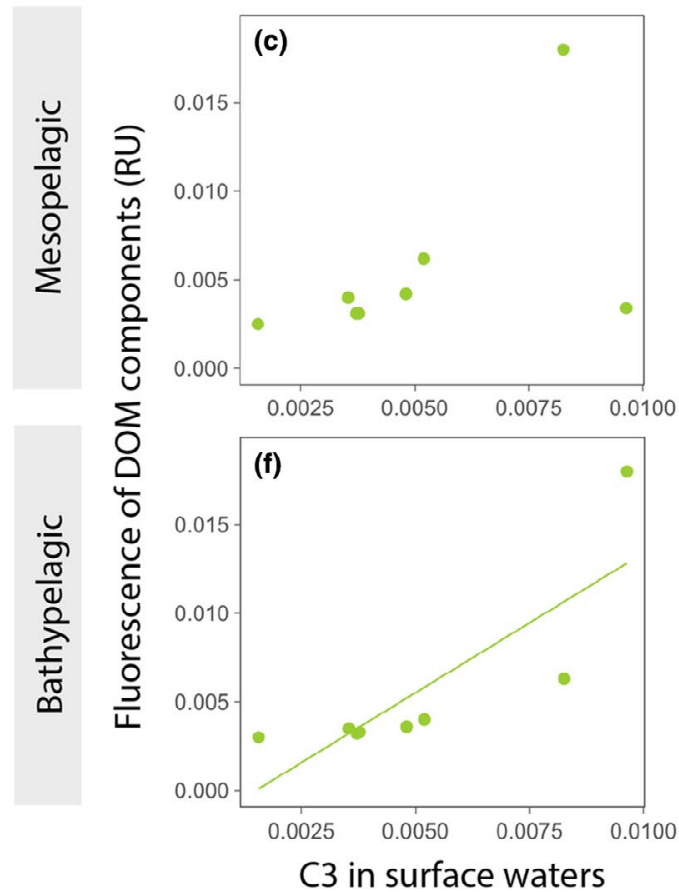

(RU)
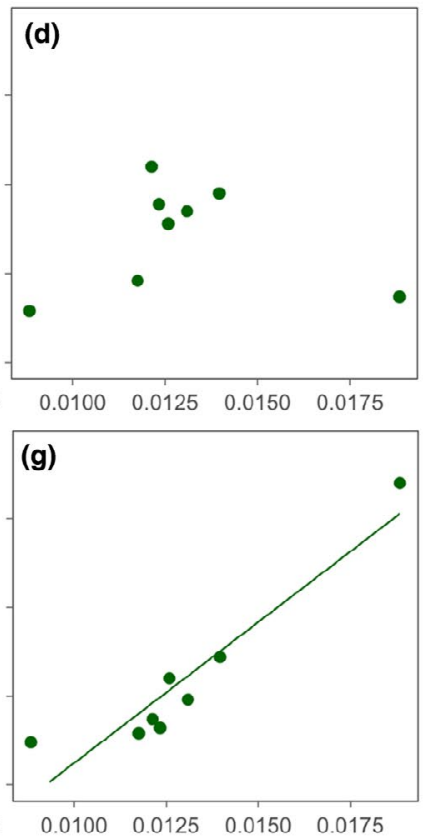

C4 in surface waters

(RU)
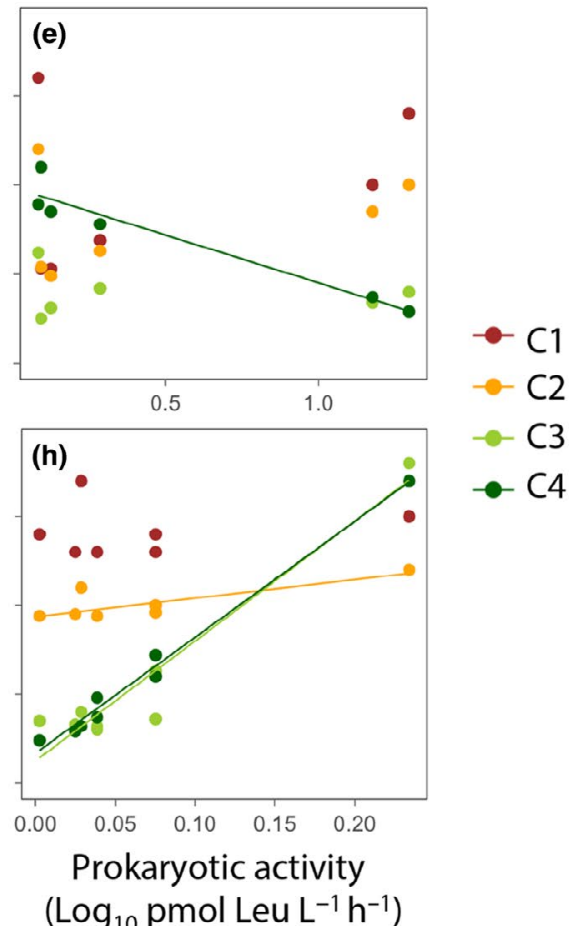

FIGURE 6 Linkages between surface and deep ocean FDOM composition drive bathypelagic prokaryotic abundance and activity. (a-b) Heatmap showing Pearson's correlation coefficients ( $R$, indicated by the colour gradient) of the linear correlations between prokaryotic abundance (a) or heterotrophic activity (b) at each depth and individual in situ physicochemical or surface variables. Only significant correlations $(p<.05)$ are shown. (c-h) Changes in the different FDOM PARAFAC components in mesopelagic (c, $d$ ) and bathypelagic (f, $g$ ) stations as a function of the amino acid-like FDOM components C 3 and C4 measured in surface waters, or as a function of the prokaryotic activity (e, h) in deep sea waters. Data are expressed as maximum fluorescence intensity of each of the four PARAFAC components in Raman units (RU). Lines are linear regressions. Only significant relationships $(p<.05)$ are shown [Colour figure can be viewed at wileyonlinelibrary.com]

as zooplankton faecal pellets is occurring (Wiedmann, Reich, Reigstad, Sundfjord, \& Basedow, 2014). In any case, nanoflagellates, ciliates or dinoflagellates have also been found in sediment traps deployed at depth (Amacher et al., 2009; Boeuf et al., 2019;
Fontánez et al., 2015; Gutiérrez-Rodríguez et al., 2019), and photosynthetic dinoflagellates represented more than $60 \%$ of the autotrophic microplankton sampled in the bathypelagic ocean in some areas of the North Atlantic and Indian Ocean during our expedition 


\section{(a) Surface-related
bathypelagic OTUs}
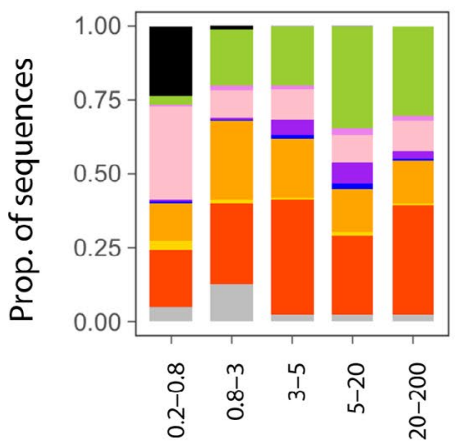

(c)

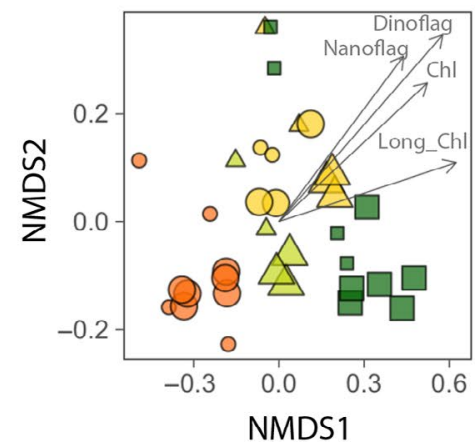

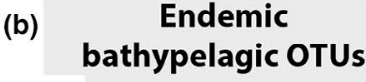

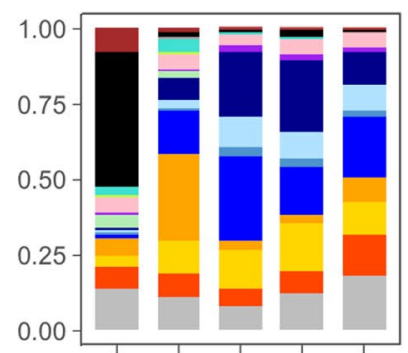

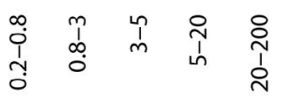

(d)

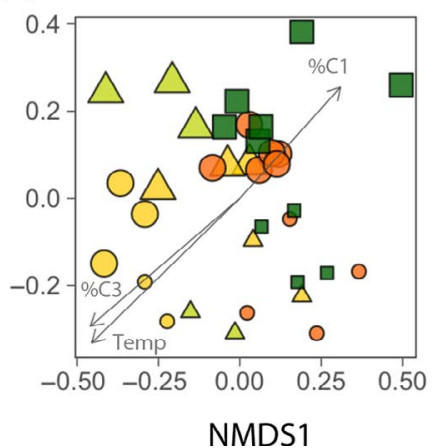

Eury/Thermoplasmata

Thaum/Marine Group I

Woesearchaeota (DHVEG-6)

Acid/Acidobacteria

Actin/Acidimicrobiia

Actin/Actinobacteria

Bact/Cytophagia

Bact/Flavobacteriia

Bact/Sphingobacteriia

- Small size-fractions
Large size-fractions

Longhurst_ChI

$\left(\mathrm{mg} / \mathrm{m}^{2}\right)$

Ocean
- Atlantic
$\square$ Indian
$\triangle$ Pacific

Chloro/SAR202 clade

Planc/OM190

Planc/Phycisphaerae

Planc/Pla3 lineage

Planc/Planctomycetacia

Prot/Alphaproteobacteria

Prot/Deltaproteobacteria

Prot/Gammaproteobacteria

Other classes

FIGURE 7 Surface-related versus endemic bathypelagic OTUs. (a-b) Taxonomic composition of surface-related (a) and endemic (b) bathypelagic OTUs across the five size-fractions. The classification was performed at the class level except for the phylum Woesearchaeota. The corresponding phylum is indicated before the name of the class: Eury, Euryarchaeota; Thaum, Thaumarchaeota; Acid, Acidobacteria; Actin, Actinobacteria; Bact, Bacteroidetes; Cya, Cyanobacteria; Chloro, Chloroflexi; Planc, Planctomycetes; Prot, Proteobacteria. Only the classes representing more that $1 \%$ of the total surface-related or endemic sequences, respectively, are presented. (c-d) NMDS ordination of bathypelagic communities considering only surface-related (c) or endemic (d) components, colour-coded according to mean annual Chl concentration $\left(\mathrm{mg} \mathrm{m}^{-2}\right.$ ) of each overlying Longhurst province. The symbols indicate the different oceans, and the symbol size indicates either small fractions (i.e., 0.2-0.8 and 0.8-3 $\mu \mathrm{m}$, small symbols) or communities attached to larger particles (i.e., 3-5, 5-20 and 20-200 $\mu \mathrm{m}$, large symbols). The arrows indicate the local environmental or surface biotic variables that fit best onto the NMDS ordination space (envfit analysis, see Section 2), and the size of the arrow is proportional to the strength of the correlation of each variable to the ordination. Temp, bathypelagic temperature; \%C1-\%C3, percentage of fluorescent FDOM components C1 and C3 in bathypelagic waters; surface abundances of dinoflagellates (Dinoflag), nanoflagellates (Nanoflag); Chl, surface measured chlorophyll-a concentration; Long_Chl, mean annual chlorophyll-a concentration of each overlying Longhurst province [Colour figure can be viewed at wileyonlinelibrary.com]

(Agustí et al., 2015). We thus cannot discard a direct contribution of these plankton groups in the downward transport of prokaryotic diversity across the global oligotrophic ocean.

When the role of in situ bathypelagic conditions and surface conditions was tested simultaneously, Longhurst-Chl emerged as the most important predictor for most particle-associated bathypelagic communities, contributing to explain up to the $98 \%$ of the BrayCurtis prokaryotic dissimilarity across bathypelagic stations. Given the generally slow growth and the potential capacity of bathypelagic prokaryotes to survive during long carbon scarcity periods (Arístegui et al., 2009; Arrieta et al., 2015; Sebastián et al., 2018, 2019), it makes sense that the local community structure is the net result of microbial responses to a mixture of recent and older particle-export episodes, which are presumably better integrated by the mean annual $\mathrm{Chl}$ associated to a given province than by the measured in situ $\mathrm{Chl}$ concentrations. As an analogous example, Hansell and Ducklow (2003) found that bathypelagic bacterial abundance in the Arabian
Sea could be better explained by the mean annual carbon flux rather than by direct measurements of episodic carbon inputs.

On the other hand, although free-living assemblages were shown to be much less vertically connected than particle-attached assemblages (Mestre et al., 2018), our results indicate that they still retain a certain surface imprint, with the abundances of surface picocyanobacteria emerging as the strongest predictors of free-living bathypelagic communities. Variations in picocyanobacteria can also be indicators of varying carbon export rates, given that small primary producers enable the formation of dense aggregates that can sink efficiently (Bach et al., 2019; Guidi et al., 2016; Richardson \& Jackson, 2007). Thus, a possibility is that a fraction of the attached communities arriving via sinking particles detaches and appears in the free-living realm (Mestre et al., 2018), explaining the signature of surface conditions on free-living taxa. Alternatively, deep-sea free-living assemblages may reflect spatial changes in the nature of organic matter or nutrients delivered to 
the bathypelagic, as suggested for shallower depths (Cram, Xia, et al., 2015; Parada \& Furhman, 2017; Richert et al., 2019; Santoro et al., 2017).

\subsection{Vertical connectivity in the oceanic DOM pool and links with bathypelagic prokaryotic activity}

We explored the latter possibility by investigating whether the nature of the DOM pool in the deep ocean could be linked to surface biotic gradients, yet we found that only variations in the local physicochemistry at each depth appeared to drive most changes in FDOM quality. However, the amino acid-like components $\mathrm{C} 3$ and $\mathrm{C} 4$ in the bathypelagic strongly followed variations in C3 and C4 in the overlying surface waters. This did not happen for the humic-like $\mathrm{C} 1$ and $\mathrm{C} 2$, which dominated the bathypelagic FDOM pool. Although the four components have been related to chlorophyll- $a$ and microbial metabolism across the global epipelagic ocean (Catalá et al., 2016), C3 and C4 are considered microbially-produced fresher labile material, whereas $\mathrm{C} 1$ and $\mathrm{C} 2$ represent more recalcitrant humic-like material (Catalá et al., 2016; Catalá, Reche, Fuentes-Lema et al. , 2015). The tight covariation of the two labile C3 and C4 FDOM components between surface and bathypelagic waters may indicate that sinking particles arriving at the deep ocean release preferentially these components, in accordance with the finding that particles reaching 4,000 m had organic carbon-specific energy values similar to surface phytoplankton (Grabowski, Letelier, Laws, \& Karl, 2019). Interestingly, changes in bathypelagic C 3 and C4 were strongly correlated with bathypelagic prokaryotic activity, suggesting that deepsea communities preferentially use these labile DOM components released from surface-derived particles. This agrees with a metaproteomics study in the Atlantic ocean showing that the microbial communities from 100 to $5,000 \mathrm{~m}$ used similar transporter proteins throughout the water column despite large changes in community structure, with amino-acid transporters showing the highest expression values at all depths (Bergauer et al., 2018). Although in situ microbial production and accumulation of DOM has been linked to the distribution of DOM across the global bathypelagic ocean (Catalá, Reche, Álvarez, et al., 2015; Catalá, Reche, Fuentes-Lema et al. , 2015), to our knowledge this is the first study comparing variations in the bathypelagic DOM pool with surface gradients in biotic properties or in the composition of DOM from overlying surface waters.

\section{3 | Stronger surface imprint on the bathypelagic than on the mesopelagic microbiome}

As it is known that most of the exported material is remineralized in mesopelagic layers and only a small fraction reaches the bathypelagic (Arístegui et al., 2009; Herndl \& Reinthaler, 2013), we expected to find a gradual loss of the surface signature towards deeper layers. However, the tight covariation between surface and bathypelagic $\mathrm{C} 3$ and C4 FDOM components was not observed in upper mesopelagic or DCM layers. Similarly, surface and bathypelagic communities from the large size-fractions showed more similar responses to surface biotic conditions than surface and DCM or mesopelagic communities. An analogous finding was reported in Pacific Ocean waters for free-living communities, where seasonality was detected at $5 \mathrm{~m}$ and $890 \mathrm{~m}$ but not in intermediate layers (Cram, Chow, et al., 2015; Cram, Xia, et al., 2015). These patterns may be explained by the existence of distinct pools of particles arriving at different depths; for example, most particles reaching the bathypelagic realm appear to be fast-sinking material of recent phytoplankton origin that escape all remineralization and transformation processes occurring in upper layers (Grabowski et al., 2019), in accordance with the recovery of intact phytoplankton cells at 4,000 m during our expedition (Agustí et al., 2015). Conversely, material in the mesopelagic may also include slowly sinking particles that can be subject to more intense microbial degradation (Grabowski et al., 2019), as well as in situ excretion of labile material by migrating zooplankters and fish that actively transport large amounts of carbon from the surface (Davison, Checkley, Koslow, \& Barlow, 2013). This presumably allows the establishment of a higher diversity of microbial niches in the mesopelagic (e.g., Calleja et al., 2018), in accordance with the higher proportion of unique or endemic OTUs (i.e., OTUs not detected in upper waters) found in the mesopelagic compared to bathypelagic assemblages (Mestre et al., 2018). Phytoplankton-derived particles sinking at fast rates, which during our expedition were estimated to range between 124 and $732 \mathrm{~m} \mathrm{day}^{-1}$ (Agustí et al., 2015), may thus comprise a direct connectivity pathway between the euphotic zone and the bathypelagic that has little influence on intermediate mesopelagic layers, governed by other processes. The tight response of bathypelagic prokaryotic activity to variations in surface-derived labile DOM components, which was not observed at any other depth, further supports a much stronger reliance of bathypelagic prokaryotes on the surface-derived sources of carbon in bathypelagic waters than of their upper layers counterparts (Arístegui et al., 2009; Herndl \& Reinthaler, 2013).

We did not consider geographic distance in our analyses due to the difficulty of determining dispersal limitation in the bathypelagic layer, where submerged landmasses and ocean circulation may determine the physical isolation between microbial communities independently of geographic position. However, we acknowledge that the patterns we show may be partially influenced by dispersal limitation. Actually, particle-attached assemblages (0.8-20 $\mu \mathrm{m})$ sampled from 30 stations during our expedition were shown to differ among bathypelagic basins, but the pure effect due to geographic distance between locations explained only $5 \%$ of the variance in community composition (Salazar, Cornejo-Castillo, Borrull, et al., 2015). In our case, the factors most strongly driving prokaryotic activity and diversity (i.e., Longhurst-Chl, phytoplankton communities or the DOM pool) did not show a clear spatial structuring (Figure 1 and Figure S2), discarding that the observed spatial distribution was entirely driven by the geographic position. We suggest instead that local or regional differences in surface particle formation and sinking determine spatial variations in the nature of the particulate or dissolved material 
reaching bathypelagic waters, as well as in the identity of the potential particle-attached colonizers.

\section{4 | Bathypelagic prokaryotes have different degrees of connectivity with surface processes}

In our previous study we showed that bathypelagic prokaryotic communities were numerically dominated by taxa present in sunlit waters, so we attributed their pronounced changes with depth to shifts in the abundances of particle-attached taxa during sinking as particle or surrounding environmental conditions change (Mestre et al., 2018). Accordingly, here we found that the surfacerelated taxa present in the bathypelagic strongly reflected surface biotic gradients and were dominated by typical copiotrophic and eukaryote-associated groups belonging to Actinobacteria, Alphaproteobacteria, Gammaproteobacteria and Flavobacteriia, in agreement with studies showing that that surface particles are first colonized by motile particle- or eukaryote-associated specialists followed by other groups of copiotrophic taxa (Datta et al., 2016; Duret, Lampitt, \& Lam, 2019; Fontánez et al., 2015; LeCleir, DeBruyn, Maas, Boyd, \& Wilhelm, 2014; Pelve et al., 2017; Thiele, Fuchs, Amann, $\&$ Iversen, 2015). If many of these taxa thrive in the bathypelagic, particle sinking might be seeding deep-sea assemblages with specific sets of microbial traits selected from within the pool of surface prokaryotes, perhaps explaining why deep-sea prokaryotes seem more adapted to the attached lifestyle than surface ones (DeLong et al., 2006; Zhao, Baltar, \& Herndl, 2020). In situations of high particle flux, however, some of these surface-related taxa may be surface prokaryotes not adapted to deep-sea conditions, as communities from surface and deeper waters were more similar in sites beneath productive epipelagic waters. Although this was only apparent for size-fractions larger than $5 \mu \mathrm{m}$, our results indicate that a fraction of the deep-sea prokaryotic diversity detected by DNA sequencing might just be a legacy of intense transport, playing no role in communities and partially obscuring our understanding of deep-sea microbial ecology.

On the other hand, some bathypelagic prokaryotes may be less directly (or less immediately) connected to surface processes if relying on metabolisms involving inorganic carbon fixation (Acinas et al., 2019; Pachiadaki et al., 2017; Swan et al., 2011), on organic carbon produced in situ by other autotrophs (Bayer et al., 2019), or on recalcitrant carbon of older origin (Landry et al., 2017). Interestingly, we identified a fraction of bathypelagic endemic taxa that were not detected in any sunlit water, and that were less strongly related to surface biotic conditions than the surface-related component; local factors such as temperature and the proportions of the FDOM components $\mathrm{C} 1$ and $\mathrm{C} 3$ in bathypelagic waters appeared as the most important drivers of the taxonomic structure of this endemic component of deep sea prokaryotic assemblages.

Endemic bathypelagic OTUs differed very clearly from the surface-related OTUs in terms of taxonomic composition. For example, groups like the Marine Group I (Thaumarchaeota), cluster SAR324 (Deltaproteobacteria), several Oceanospirillales (Gammaproteobacteria) and Planctomycetes dominated this endemic bathypelagic pool, many of which are known to contain organisms capable of fixing inorganic carbon using energy from the oxidation of substrates, such as ammonium, nitrite, and reduced sulfur compounds (Beman, Leilei, \& Popp, 2013; Pachiadaki et al., 2017; Reinthaler, van Aken, \& Herndl, 2010; Swan et al., 2011). An indirect inference of the potential functions based on the taxonomy of these OTUs supported a higher proportion of chemoautotrophic metabolisms among the endemic than among the surface-related taxa, which may explain a less tight dependence of endemic bathypelagic OTUs on freshly arrived surface carbon, and thus a decoupling from surface processes. For prokaryotes associated with the large particles, the proportion of autotrophic metabolisms was higher beneath the most oligotrophic provinces, both in the surface-related and in the endemic bathypelagic taxa. Although we are aware that these results can be biased depending on the genomic information available (Louca et al., 2016), they suggest that a less intense flux of organic carbon might promote a higher metabolic versatility among bathypelagic prokaryotes, allowing them to exploit a wider variety of carbon or energy sources.

Both endemic and surface-related bathypelagic groups were present across all size fractions, so endemic particle-attached prokaryotes might represent bathypelagic taxa that colonize older suspended particles resulting from the disaggregation of the sinking ones, or which might be autochthonously produced (Herndl \& Reinthaler, 2013). In support of this hypothesis, microbial communities associated to suspended or sinking mesopelagic particles were found to differ in their structure, and the differences were attributed to variations in organic matter quality and freshness (Duret et al., 2019). In any case, the fact that even the structure and activity of free-living bathypelagic communities retain a certain surface signature, coupled to the notion that particles are hotspots for microbial life and activity in the deep ocean (Bochdansky, Clouse, \& Herndl, 2016; Herndl \& Reinthaler, 2013), suggest that surface conditions play a key role in shaping the diversity and functioning of the bathypelagic microbiome.

In conclusion, we show that bathypelagic prokaryotes to a large extent mirror the spatial variations in surface biotic conditions such as the structure of phytoplankton communities in overlying sunlit waters, likely as a consequence of surface particle formation processes, colonization and downward dispersal. These surface conditions are more important drivers of spatial changes in deep ocean prokaryotic structure than environmental factors within the bathypelagic layer, particularly for prokaryotes attached to the largest particles, but even free-living assemblages retain a certain surface imprint. The fluorescence intensity of amino acid-like DOM components in bathypelagic waters seems to originate from surface-produced material and apparently controls bathypelagic prokaryotic activity. Fast-sinking particles may comprise a direct connection pathway between the epipelagic and bathypelagic ocean with little influence on mesopelagic prokaryotes, which are presumably more influenced by slower and older sinking material 
or by mesopelagic-specific processes, such as zooplankton and fish diel vertical migration. We finally postulate that the local structure of bathypelagic communities is composed by a mixture of taxa with different origins and lifestyles, each differently related to surface processes: A surface-related component, comprising prokaryotes arriving via sinking particles, which seem largely structured by the nature of the exported material, and a pool of endemic taxa, perhaps reliant to a larger extent on chemoautotrophic metabolisms or on recalcitrant compounds, which appear less tightly (or less immediately) connected to surface biological processes.

\section{ACKNOWLEDGEMENTS}

This work was funded by the Spanish Ministry of Economy and Competitiveness (MINECO) through the Consolider-Ingenio program (Malaspina 2010 Expedition, ref. CSD2008-00077), with contributions from grant CTM2015-70340R, CTM2015-65720-R, CTM2015-69936-P, RTI2018-101025-B-I00, Modelling Nature Scientific Unit (UCE.PP2017.03), CTM2015-69392-C3-2-R (cofinanced with FEDER funds) and King Abdullah University of Science and Technology (KAUST). We thank all scientists and crew involved in the Malaspina expedition, particularly A. Gomes, T. S. Catalá, M. Pernice, F. M. Cornejo-Castillo, E. Borrull, C. Antequera, C. Díez-Vives, E. Lara, M. R. Logares, P. Sánchez, A. Fuentes-Lema, C. Marrasé, M. Nieto-Cid, E. Ortega-Retuerta and C. Romera-Castillo and D. Vaqué for help with DNA collection, sequence data treatment, bacterial activity determinations, and FDOM determinations. This is a contribution of Grup Consolidat de Recerca of the Catalan Government 2014SGR/1179. CRG was supported by a Juan de la Cierva fellowship and the GRAMMI project (IJCI-2015-23505 and RTI2018-099740-J-I00, MICINN, Spain). MSE was supported by a Viera y Clavijo contract funded by the ACIISI and the ULPGC. MM was supported by CONICYT (FONDAP-IDEAL15150003 and FONDECYT-POSTDOCTORADO 3190369).

\section{AUTHOR CONTRIBUTIONS}

J.M.G., C.M.D., M.M.S., and M.M. participated in the design of the expedition and/or designed the sampling scheme. M.M., and G.S. prepared the DNA samples on board. M.M. extracted the DNA and processed the prokaryotic diversity data. M.E., S.A., and E.M.O., processed and provided phytoplankton data. G.S. performed the GDM statistical analyses. X.A.S., and I.R. processed and provided DOM composition data and X.A.G.M., and J.M.G. the bacterial activity data, respectively. M.S. conducted the functional annotation of taxa. C.R.G conceived the idea of the manuscript, compiled the needed data, analysed them and wrote this article. All authors made relevant comments and editions to the text.

\section{DATA AVAILABILITY STATEMENT}

DNA sequences and associated metadata: European Nucleotide Database (ENA) under accession numbers ERP109198 and ERS2539749-ERS2539903. The environmental metadata, and the complete nonrarefied OTU and taxonomic tables used in this study are provided as Tables S1-S4.

\section{ORCID}

Clara Ruiz-González iD https://orcid.org/0000-0003-3568-4943

Mireia Mestre iD https://orcid.org/0000-0003-0986-633X

Marta Estrada iD https://orcid.org/0000-0001-5769-9498

Marta Sebastián iD https://orcid.org/0000-0001-7175-8941

Guillem Salazar iD https://orcid.org/0000-0002-9786-1493

Susana Agustí iD https://orcid.org/0000-0003-0536-7293

Enrique Moreno-Ostos (iD https://orcid.org/0000-0001-9471-3922

Isabel Reche iD https://orcid.org/0000-0003-2908-1724

Xosé Antón Álvarez-Salgado (iD https://orcid.

org/0000-0002-2387-9201

Xosé Anxelu G. Morán iD https://orcid.org/0000-0002-9823-5339

Carlos M. Duarte iD https://orcid.org/0000-0002-1213-1361

M. Montserrat Sala iD https://orcid.org/0000-0002-3804-5680

Josep M. Gasol iD https://orcid.org/0000-0001-5238-2387

\section{REFERENCES}

Acinas, S. G., Sánchez, P., Salazar, G., Cornejo-Castillo, F. M., Sebastián, M., Logares, R., Gasol, J. M. (2019). Metabolic architecture of the deep ocean microbiome. bioRxiv. https://doi.org/10.1101/635680

Agusti, S., González-Gordillo, J. I., Vaqué, D., Estrada, M., Cerezo, M. I., Salazar, G., ... Duarte, C. M. (2015). Ubiquitous healthy diatoms in the deep sea confirm deep carbon injection by the biological pump. Nature Communications, 6, 7608. https://doi.org/10.1038/ncomm s8608

Agustí, S., Lubián, L., Moreno-Ostos, E., Estrada, M., \& Duarte, C. M. (2019). Projected changes in photosynthetic picoplankton in a warmer subtropical ocean. Frontiers in Marine Science, 5, 506. https:// doi.org/10.3389/fmars.2018.00506

Al-Mutairi, H., \& Landry, M. R. (2001). Active export of carbon and nitrogen at Station ALOHA by diel migrant zooplankton. Deep Sea Research Part II, 48, 2083-2103. https://doi.org/10.1016/S0967 -0645(00)00174-0

Amacher, J., Neuer, S., Anderson, I., \& Massana, R. (2009). Molecular approach to determine contributions of the protist community to particle flux. Deep Sea Research Part I Oceanographic Research Papers, 56, 2206-2215. https://doi.org/10.1016/j.dsr.2009.08.007

Arístegui, J., Agustí, S., Middelburg, J. J., \& Duarte, C. M. (2005). Respiration in the mesopelagic and bathypelagic zones of the ocean. In P. A. Del Giorgio, \& P. J. L. Williams (Eds.), Respiration in aquatic ecosystems (pp. 181-205). Oxford: Oxford University Press.

Arístegui, J., Gasol, J. M., Duarte, C. M., \& Herndl, G. J. (2009). Microbial oceanography of the dark ocean's pelagic realm. Limnology and Oceanography, 54, 1501-1529. https://doi.org/10.4319/ lo.2009.54.5.1501

Arrieta, J. M., Mayol, E., Hansman, R. L., Herndl, G. J., Dittmar, T., \& Duarte, C. M. (2015). Dilution limits dissolved organic carbon utilization in the deep ocean. Science, 348, 331-333. https://doi. org/10.1126/science.1258955

Bach, L. T., Boxhammer, T., Larsen, A., Hildebrand, N., Schultz, K. G., \& Riebesell, U. (2016). Influence of plankton community structure on the sinking velocity of marine aggregates. Global Biogeochemical Cycles, 30, 1145-1165. https://doi.org/10.1002/2016GB005372

Bach, L. T., Stange, P., Taucher, J., Achterberg, E. P., Algueró-Muñiz, M., Horn, H., ... Riebesell, U. (2019). The Influence of Plankton Community Structure on Sinking Velocity and Remineralization Rate of Marine Aggregates. Global Biogeochemical Cycles, 33, 971-994. https://doi.org/10.1029/2019GB006256

Baltar, F., Arístegui, J., Gasol, J. M., Sintes, E., \& Herndl, G. J. (2009). Evidence of prokaryotic metabolism on suspended particulate organic matter in the dark waters of the subtropical North Atlantic. 
Limnology and Oceanography, 54, 182-193. https://doi.org/10.4319/ lo.2009.54.1.0182

Bayer, B., Hansman, R. L., Bittner, M. J., Noriega-Ortega, B. E., Niggemann, J., Dittmar, T., \& Herndl, G. J. (2019). Ammonia-oxidizing archaea release a suite of organic compounds potentially fueling prokaryotic heterotrophy in the ocean. Environmental Microbiology, 21, 4062-4075. https://doi.org/10.1101/558726

Beman, M., Leilei, J., \& Popp, B. N. (2013). Nitrite oxidation in the upper water column and oxygen minimum zone of the eastern tropical North Pacific Ocean. The ISME Journal, 7, 2192-2205. https://doi. org/10.1038/ismej.2013.96

Bergauer, K., Fernandez-Guerra, A., Garcia, J. A. L., Sprenger, R. R., Stepanauskas, R., Pachiadaki, M. G., ... Herndl, G. J. (2018). Organic matter processing by microbial communities throughout the Atlantic water column as revealed by metaproteomics. Proceedings National Academy of Sciences USA, 115, E400-E408. https://doi.org/10.1073/ pnas. 1708779115

Bochdansky, A. B., Clouse, M. A., \& Herndl, G. J. (2016). Dragon kings of the deep sea: Marine particles deviate markedly from the common number-size spectrum. Scientific Reports, 6, 22633. https://doi. org $/ 10.1038 /$ srep22633

Boeuf, D., Edwards, B. R., Eppley, J. M., Hu, S. K., Poff, K. E., Romano, A. E., ... DeLong, E. F. (2019). Biological composition and microbial dynamics of sinking particulate organic matter at abyssal depths in the oligotrophic open ocean. Proceedings of the National Academy of Sciences USA, 116, 11824-11832. https://doi.org/10.1073/ pnas.1903080116

Boyd, P. W., \& Newton, P. (1995). Evidence of the potential influence of planktonic community structure on the interannual variability of particulate organic carbon flux. Deep Sea Research Part I Oceanographic Research Papers, 42, 619-639. https://doi.org/10.1016/09670637(95)00017-Z

Calleja, M. L., Ansari, M. I., Røstad, A., Silva, L., Kaartvedt, S., Irigoien, X., \& Morán, X. A. G. (2018). The Mesopelagic Scattering Layer: A Hotspot for Heterotrophic Prokaryotes in the Red Sea Twilight Zone. Frontiers in Marine Science, 5. https://doi.org/10.3389/ fmars.2018.00259

Catalá, T. S., Álvarez-Salgado, X. A., Otero, J., luculano, F., Companys, B., Horstkotte, B., ... Reche, I. (2016). Drivers of fluorescent dissolved organic matter in the global epipelagic ocean. Limnology and Oceanography, 61, 1101-1119. https://doi.org/10.1002/Ino.10281

Catalá, T. S., Reche, I., Álvarez, M., Khatiwala, S., Guallart, E. F., BenítezBarrios, V. M., ... Álvarez-Salgado, X. A. (2015). Water mass age and aging driving chromophoric dissolved organic matter in the dark global ocean. Global Biogeochemical Cycles, 29, 917-934. https://doi. org/10.1002/2014GB005048

Catalá, T. S., Reche, I., Fuentes-Lema, A., Romera-Castillo, C., Nieto-Cid, M., Ortega-Retuerta, E., ... Alvarez-Salgado, X. A. (2015). Turnover time of fluorescent dissolved organic matter in the dark global ocean. Nature Communications, 6(1), 1-9. https://doi.org/10.1038/ncomm s6986

Clarke, K., \& Ainsworth, M. (1993). A method of linking multivariate community structure to environmental variables. Marine Ecology Progress Series, 92, 205-219. https://doi.org/10.3354/meps092205

Cram, J. A., Chow, C. E. T., Sachdeva, R., Needham, D. M., Parada, A. E., Steele, J. A., \& Furhman, J. A. (2015). Seasonal and interannual variability of the marine bacterioplankton community throughout the water column over ten years. The ISME Journal, 9, 563-580. https:// doi.org/10.1038/ismej.2014.153

Cram, J. A., Xia, L. C., Needham, D. M., Sachdeva, R., Sun, F., \& Fuhrman, J. A. (2015). Cross-depth analysis of marine bacterial networks suggests downward propagation of temporal changes. The ISME Journal, 9, 2573-2586. https://doi.org/10.1038/ismej.2015.76

Datta, M. S., Sliwerska, E., Gore, J., Polz, M. F., \& Cordero, O. X. (2016). Microbial interactions lead to rapid micro-scale successions on model marine particles. Nature Communications, 7, 11965. https:// doi.org/10.1038/ncomms11965

Davison, P. C., Checkley, D. M., Koslow, J. A., \& Barlow, J. (2013). Carbon export mediated by mesopelagic fishes in the northeast Pacific Ocean. Progress in Oceanography, 116, 14-30. https://doi. org/10.1016/j.pocean.2013.05.013

DeLong, E. F., Preston, C. M., Mincer, T., Rich, V., Hallam, S. J., Frigaard, N. U., ... Karl, D. M. (2006). Community genomics among stratified microbial assemblages in the ocean's interior. Science, 311, 496-503. https://doi.org/10.1126/science.1120250

Duarte, C. M. (2015). Seafaring in the 21st century: The Malaspina 2010 Circumnavigation Expedition. Limnology and Oceanography Bulletin, 24, 11-14. https://doi.org/10.1002/lob.10008

Duret, M. T., Lampitt, R. S., \& Lam, P. (2019). Prokaryotic niche partitioning between suspended and sinking marine particles. Environmental Microbiology Reports, 11, 386-400. https://doi. org/10.1111/1758-2229.12692

Estrada, M., Delgado, M., Blasco, D., Latasa, M., Cabello, A. M., Benítez-Barrios, V., ... Vidal, M. (2016). Phytoplankton across tropical and subtropical regions of the Atlantic, Indian and Pacific Oceans. PLoS ONE, 11, e0151699. https://doi.org/10.1371/journ al.pone. 0151699

Fender, C., Kelly, T. B., Guidi, L., Ohman, M. D., Smith, M. C., \& Stukel, M. R. (2019). Investigating particle size-flux relationships and the biological pump across a range of plankton ecosystem states from coastal to oligotrophic. Frontiers in Aquatic Sciences, 6, 603. https:// doi.org/10.3389/fmars.2019.00603

Ferrier, S., Manion, G., Elith, J., \& Richardson, K. (2007). Using generalized dissimilarity modelling to analyse and predict patterns of beta diversity in regional biodiversity assessment. Diversity and Distributions, 13, 252-264. https://doi.org/10.1111/j.1472-4642.2007.00341.x

Fontánez, K. M., Eppley, J. M., Samo, T. J., Karl, D. M., \& DeLong, E. F. (2015). Microbial community structure and function on sinking particles in the North Pacific Subtropical Gyre. Frontiers in Microbiology, 6, 1-14. https://doi.org/10.3389/fmicb.2015.00469

Garcia, H. E., Locarnini, R. A., Boyer, T. P., Antonov, J. I., Baranova, O. K., Zweng, M. M., Johnson, D. R. (2014). World Ocean Atlas 2013. In S. Levitus (Ed.), Dissolved Inorganic Nutrients (phosphate, nitrate, silicate), Vol. 76 (pp. 25). Silver Spring, MD: NOAA Atlas NESDIS.

Gasol, J. M., \& Del Giorgio, P. A. (2000). Using flow cytometry for counting natural planktonic bacteria and understanding the structure of planktonic bacterial communities. Scientia Marina, 64, 197-224. https://doi.org/10.3989/scimar.2000.64n2197

Grabowski, E., Letelier, R. M., Laws, E. A., \& Karl, D. (2019). Coupling carbon and energy fluxes in the North Pacific Subtropical Gyre. Nature Communications, 10, 1895. https://doi.org/10.1038/s41467-01909772-z

Grossart, H. P., Levold, F., Allgaier, M., Simon, M., \& Brinkhoff, T. (2005). Marine diatom species harbour distinct bacterial communities. Environmental Microbiology, 7, 860-873. https://doi. org/10.1111/j.1462-2920.2005.00759.x

Guidi, L., Chaffron, S., Bittner, L., Eveillard, D., Larhlimi, A., Roux, S., ... Gorsky, G. (2016). Plankton networks driving carbon export in the oligotrophic ocean. Nature, 532, 465-470. https://doi.org/10.1038/ nature16942

Guidi, L., Stemmann, L., Jackson, G. A., Ibanez, F., Claustre, H., Legendre, L., ... Gorskya, G. (2009). Effects of phytoplankton community on production, size and export of large aggregates: A world-ocean analysis. Limnology and Oceanography, 54, 1951-1963. https://doi. org/10.4319/lo.2009.54.6.1951

Gutiérrez-Rodríguez, A., Stukel, M. R., Lopes dos Santos, A., Biard, T., Scharek, R., Vaulot, D., ... Not, F. (2019). High contribution of Rhizaria (Radiolaria) to vertical export in the California Current Ecosystem revealed by DNA metabarcoding. The ISME Journal, 13, 964-976. https://doi.org/10.1038/s41396-018-0322-7 
Hansell, D. A., Carlson, C. A., Bates, N. R., \& Poisson, A. (1997). Horizontal and vertical removal of organic carbon in the equatorial Pacific Ocean: A mass balance assessment. Deep Sea Research Part II, 44, 2115-2130. https://doi.org/10.1016/S0967-0645(97)00021-0

Hansell, D. A., \& Ducklow, H. W. (2003). Bacterioplankton distribution and production in the bathypelagic ocean: Directly coupled to particulate organic carbon export? Limnology and Oceanography, 48, 150-156. https://doi.org/10.4319/lo.2003.48.1.0150

Hansen, A. S., Ohde, T., \& Wasmund, N. (2014). Succession of micro- and nanoplankton groups in ageing upwelled waters off Namibia. Journal of Marine Systems, 140, 130-137. https://doi.org/10.1016/j.jmars ys.2014.05.003

Herndl, G. J., \& Reinthaler, T. (2013). Microbial control of the dark end of the biological pump. Nature Geoscience, 6, 718-724. https://doi. org/10.1038/ngeo1921

Kirchman, D., Knees, E., \& Hodson, R. (1985). Leucine incorporation and its potential as a measure of protein-synthesis by bacteria in natural aquatic systems. Applied and Environmental Microbiology, 49, 599607. https://doi.org/10.1128/AEM.49.3.599-607.1985

Landry, Z. C., Swan, B. K., Herndl, G. J., Stepanauskas, R., \& Giovannoni, S. J. (2017). SAR202 Genomes from the Dark Ocean Predict Pathways for the Oxidation of Recalcitrant Dissolved Organic Matter. Mbio, 8(2), e00413-e417. https://doi.org/10.1128/mBio.00413-17

Laurenceau-Cornec, E. C., Trull, T. W., Davies, D. M., De la Rocha, C. L., \& Blain, S. (2015). Phytoplankton morphology controls on marine snow sinking velocity. Marine Ecology-Progress Series, 520, 35-56. https:// doi.org/10.3354/meps11116

LeCleir, G. R., DeBruyn, J. M., Maas, E. W., Boyd, P. W., \& Wilhelm, S. W. (2014). Temporal changes in particle-associated microbial communities after interception by nonlethal sediment traps. FEMS Microbiology Ecology, 87, 153-163. https://doi.org/10.1111/1574-6941.12213

Longhurst, A. (1998). Ecological geography of the sea. San Diego, CA: Academic Press.

Louca, S., Wegener-Parfrey, L., \& Doebeli, M. (2016). Decoupling function and taxonomy in the global ocean microbiome. Science, 353, 1272-1277. https://doi.org/10.1126/science.aaf4507

Lundgreen, R. B. C., Jaspers, C., Traving, S. J., Ayala, D. J., Lombard, F., Grossart, H.-P., ... Riemann, L. (2019). Eukaryotic and cyanobacterial communities associated with marine snow particles in the oligotrophic sargasso sea. Scientific Reports, 9, 8891. https://doi. org/10.1038/s41598-019-45146-7

Manion, G., Lisk, M., Ferrier, S., Nieto-Lugilde, D., Mokany, K., \& Fitzpatrick, M. C. (2018). dgm: Generalized dissimilarity modeling. R package 1.3.8.

Mestre, M. (2018). 16S rDNA genes from different size-fraction across vertical profiles in the global ocean sampled during the Malaspina 2010 expedition. European Nucleotide Database (ENA). https://www.ebi.ac.uk/ ena/data/view/PRJEB27154

Mestre, M., Ruiz-González, C., Logares, R., Duarte, C. M., Gasol, J. M., \& Sala, M. M. (2018). Sinking particles promote vertical connectivity in the ocean microbiome. Proceedings of the National Academy of Sciences USA, 115, E6799-E6807. https://doi.org/10.1073/ pnas.1802470115

Morán, X. A. G., Gasol, J. M., Pernice, M. C., Mangot, J.-F., Massana, R., Lara, E., ... Duarte, C. M. (2017). Temperature regulation of marine heterotrophic prokaryotes increases latitudinally as a breach between bottom-up and top-down controls. Global Change Biology, 23 , 3956-3964. https://doi.org/10.1111/gcb.13730

Nagata, T., Fukuda, H., Fukuda, R., \& Koike, I. (2000). Bacterioplankton distribution and production in deep Pacific waters: Large-scale geographic variations and possible coupling with sinking particle fluxes. Limnology and Oceanography, 42, 426-435. https://doi.org/10.4319/ lo.2000.45.2.0426

Oksanen, J., Blanchet, F. G., Kindt, R., Legendre, P., Minchin, P. R., O'Hara, R. B., ... Wagner, H. (2015). Vegan: Community Ecology Package. R package version 2.3-2.
Pachiadaki, M. G., Sintes, E., Bergauer, K., Brown, J. M., Record, N. R., Swan, B. K., ... Stepanauskas, R. (2017). Major role of nitrite-oxidizing bacteria in dark ocean carbon fixation. Science, 358, 1046-1051. https://doi.org/10.1126/science.aan8260

Parada, A. E., \& Furhman, J. A. (2017). Marine archaeal dynamics and interactions with the microbial community over 5 years from surface to seafloor. The ISME Journal, 11, 2510-2525. https://doi.org/10.1038/ ismej.2017.104

Parada, A. E., Needham, D. M., \& Fuhrman, J. A. (2016). Every base matters: Assessing small subunit rRNA primers for marine microbiomes with mock communities, time series and global field samples. Environmental Microbiology, 18, 1403-1414. https://doi. org/10.1111/1462-2920.13023

Pelve, E. A., Fontánez, K. M., \& DeLong, E. F. (2017). Bacterial succession on sinking particles in the ocean's Interior. Frontiers in Microbiology, 8 , 2269. https://doi.org/10.3389/fmicb.2017.02269

Pernice, M. C., Forn, I., Gomes, A., Lara, E., Alonso-Sáez, L., Arrieta, J. M., ... Massana, R. (2015). Global abundance of planktonic heterotrophic protists in the deep ocean. The ISME Journal, 9, 782-792. https://doi. org/10.1038/ismej.2014.168

Pernice, M. C., Giner, C. R., Logares, R., Perera-Bel, J., Acinas, S. G., Duarte, C. M., ... Massana, R. (2016). Large variability of bathypelagic microbial eukaryotic communities across the world's oceans. The ISME Journal, 10, 945-958. https://doi.org/10.1038/ismej.2015.170

Piwosz, K., Shabarova, T., Pernthaler, J., Posch, T., Šimek, K., Porcal, P., \& Salcher, M. M. (2020). Bacterial and Eukaryotic SmallSubunit Amplicon Data Do Not Provide a Quantitative Picture of Microbial Communities, but They Are Reliable in the Context of Ecological Interpretations. mSphere, 5(2), e00052-e120. https://doi. org/10.1128/mSphere.00052-20

R Core Team (2013). R: A Language and Environment for Statistical Computing. Vienna, Austria: R Foundation for Statistical Computing. http://www.R-project.org/

Reinthaler, T., van Aken, H., \& Herndl, G. J. (2010). Major contribution of autotrophy to microbial carbon cycling in the deep North Atlantic's interior. Deep Sea Research Part II, 57, 1572-1580. https://doi. org/10.1016/j.dsr2.2010.02.023

Richardson, T. L., \& Jackson, G. A. (2007). Small phytoplankton and carbon export from the surface ocean. Science, 315, 838-840. https:// doi.org/10.1126/science.1133471

Richert, I., Yager, P. L., Dinasquet, J., Logares, R., Riemann, L., Wendeberg, A., ... Scofield, D. G. (2019). Summer comes to the Southern Ocean: How phytoplankton shape bacterioplankton communities far into the deep dark sea. Ecosphere, 10, e02641. https://doi.org/10.1002/ ecs2.2641

Salazar, G., Cornejo-Castillo, F. M., Benítez-Barrios, V., Fraile-Nuez, E., Álvarez-Salgado, X. A., Duarte, C. M., ... Acinas, S. G. (2015). Global diversity and biogeography of deep-sea pelagic prokaryotes. The ISME Journal, 10, 596-608. https://doi.org/10.1038/ismej.2015.137

Salazar, G., Cornejo-Castillo, F. M., Borrull, E., Díez-Vives, C., Lara, E., Vaqué, D., ... Acinas, S. G. (2015). Particle-association lifestyle is a phylogenetically conserved trait in bathypelagic prokaryotes. Molecular Ecology, 24, 5692-5706. https://doi.org/10.1111/mec.13419

Santoro, A. E., Saito, M. A., Goepfert, T. J., Lamborg, C. H., Dupont, C. L., \& DiTullio, G. (2017). Thaumarchaeal ecotype distributions across the equatorial Pacific Ocean and their potential roles in nitrification and sinking flux attenuation. Limnology and Oceanography, 62, 19842003. https://doi.org/10.1002/Ino.10547

Schmoker, C., Ojeda, A., \& Hernandez-Leon, S. (2014). Patterns of plankton communities in subtropical waters off the Canary Islands during the late winter bloom. Journal of Sea Research, 85, 155-161. https:// doi.org/10.1016/j.seares.2013.05.002

Sebastián, M., Auguet, J.-C., Restrepo-Ortiz, C. X., Sala, M. M., Marrasé, C., \& Gasol, J. M. (2018). Deep ocean prokaryotic communities are remarkably malleable when facing long-term 
starvation. Environmental Microbiology, 20, 713-723. https://doi. org/10.1111/1462-2920.14002

Sebastián, M., Estrany, M., Ruiz-González, C., Forn, I., Sala, M., Gasol, J. M., \& Marrasé, C. (2019). High Growth Potential of Long-Term Starved Deep Ocean Opportunistic Heterotrophic Bacteria. Frontiers in Microbiology, 10, 760. https://doi.org/10.3389/fmicb.2019.00760

Shih, Y., Lin, H., Li, D., Hsieh, H., Hung, C., \& Chen, C. T. A. (2019). Elevated carbon flux in deep waters of the South China Sea. Scientific Reports, 9, 1496. https://doi.org/10.1038/s41598-018-37726-w

Sison-Mangus, M. P., Jiang, S., Kudela, R. M., \& Mehic, S. (2016). Phytoplankton-associated bacterial community composition and succession during toxic diatom bloom and non-bloom events. Frontiers in Microbiology, 7, 1433. https://doi.org/10.3389/fmicb.2016.01433

Smith, D., \& Azam, F. (1992). A simple, economical method for measuring bacteria protein synthesis rates in seawater using $3 \mathrm{H}$-leucine. Marine Microbial Food Webs, 6, 107-114.

Stukel, M. R., Landry, M. R., Benitez-Nelson, C. R., \& Goericke, R. (2011). Trophic cycling and carbon export relationships in the California Current Ecosystem. Limnology and Oceanography, 56, 1866-1878. https://doi.org/10.4319/lo.2011.56.5.1866

Swan, B. K., Martinez-Garcia, M., Preston, C. M., Sczyrba, A., Woyke, T., Lamy, D., ... Stepanauskas, R. (2011). Potential for chemolithoautotrophy among ubiquitous bacteria lineages in the dark ocean. Science, 333, 1296-1299. https://doi.org/10.1126/science.1203690

Tamburini, C., Garcin, J., \& Bianchi, A. (2003). Role of deep-sea bacteria in organic matterb mineralization and adaptation to hydrostatic pressure conditions in the NW Mediterranean Sea. Aquatic Microbial Ecology, 32, 209-218.

Thiele, S., Fuchs, B. M., Amann, R., \& Iversen, M. H. (2015). Colonization in the photic zone and subsequent changes during sinking determine bacterial community Composition in Marine Snow. Applied and
Environmental Microbiology, 81, 1463-1471. https://doi.org/10.1128/ AEM.02570-14

Wiedmann, I., Reich, P., Reigstad, M., Sundfjord, A., \& Basedow, S. (2014). Potential drivers of sinking particle's size spectra and vertical flux of particulate organic carbon (POC): Turbulence, phytoplankton, and zooplankton. Journal of Geophysical Research, 119, 6900-6917. https://doi.org/10.1002/2013JC009754

Yokokawa, T., Yang, Y. H., Motegi, C., \& Nagata, T. (2013). Large-scale geographical variation in prokaryotic abundance and production in meso- and bathypelagic zones of the central Pacific and Southern Ocean. Limnology and Oceanography, 58, 61-73. https://doi. org/10.4319/lo.2013.58.1.0061

Zhao, Z., Baltar, F., \& Herndl, G. J. (2020). Linking extracellular enzymes to phylogeny indicates a predominantly particle-associated lifestyle of deep-sea prokaryotes. Science Advances, 6, eaaz4354. https://doi. org/10.1126/sciadv.aaz4354

\section{SUPPORTING INFORMATION}

Additional supporting information may be found online in the Supporting Information section.

How to cite this article: Ruiz-González C, Mestre M, Estrada

$\mathrm{M}$, et al. Major imprint of surface plankton on deep ocean prokaryotic structure and activity. Mol Ecol. 2020;29:18201838. https://doi.org/10.1111/mec.15454 